University of Louisville

ThinkIR: The University of Louisville's Institutional Repository

Electronic Theses and Dissertations

$12-2011$

\title{
Age-associated changes in innate immunity and their impacts on inflammatory disease.
}

Mehmet Akif Eskan

University of Louisville

Follow this and additional works at: https://ir.library.louisville.edu/etd

\section{Recommended Citation}

Eskan, Mehmet Akif, "Age-associated changes in innate immunity and their impacts on inflammatory disease." (2011). Electronic Theses and Dissertations. Paper 410.

https://doi.org/10.18297/etd/410

This Doctoral Dissertation is brought to you for free and open access by ThinkIR: The University of Louisville's Institutional Repository. It has been accepted for inclusion in Electronic Theses and Dissertations by an authorized administrator of ThinkIR: The University of Louisville's Institutional Repository. This title appears here courtesy of the author, who has retained all other copyrights. For more information, please contact thinkir@louisville.edu. 


\title{
AGE-ASSOCIATED CHANGES IN INNATE IMMUNITY AND THEIR IMPACTS ON INFLAMMATORY DISEASE
}

\author{
By \\ Mehmet Akif Eskan DDS \\ 319 Abraham Flexner Way, 55A Rm 405 \\ University of Louisville, 2011
}

\author{
A Dissertation \\ Submitted to the School of Medicine \\ University of Louisville in Partial Fulfillment of the Requirement \\ For the Degree
}

Doctor of Philosophy

Department of Microbiology \& Immunology

December 2011 


\title{
AGE-ASSOCIATED CHANGES IN INNATE IMMUNITY AND THEIR IMPACTS ON INFLAMMATORY DISEASES
}

\author{
By \\ Mehmet Akif Eskan DDS \\ 319 Abraham Flexner Way, 55A Rm 405 \\ University of Louisville, 2011
}

A Dissertation Approved on

November 3, 2011

By the following Dissertation Committee:

George N Hajishengallis PhD

Dissertation Director

Thomas C MitchelrPhD

Co-Advisor

Jill Suttles PhD

Robert D Stout PhD

Silvia M Uriarte $\mathrm{PhD}$ 


\section{DEDICATION}

To my beautiful wife Eylul Eskan MD 


\section{ACKNOWLEDGMENTS}

I would like to thank my advisor George $N$ Hajihengallis DDS, PhD. This dissertation would not have happened without his guidance and the help. I would also like to thank the other committee members, Thomas $\mathrm{C}$ Mitchell $\mathrm{PhD}$, Jill Suttles $\mathrm{PhD}$, Robert $\mathrm{D}$ Stout $\mathrm{PhD}$ and Silvia M Uriarte $\mathrm{PhD}$. I would like to express my thanks to my wife, Eylul, for her understanding and patience during those times when I saw no light at the end. I would like to thank my friend, Edip, who did not hesitate to pick the phone whenever I needed his invaluable insights and expertise. Finally, I would like to thank to my clinical professor, Dr Henry Greenwell. He encouraged me to start the PhD program and to come to this point. I will never forget what he had been done for me. I like to thank Ravi for sharing his expertise on immuno-histochemistry and confocal. I like to thank Toshi for his great help in the microinjection assays. I like to thank Li for her great help in animal breeding and maintenance. I like to thank to Shuang for sharing his knowledge all the time. I like to thank to Paul for helping in this project. I like to thank Megan for helping me on the Del-1 intervention assay during the evenings and weekends and finally I like to thank to Jennifer for helping on this project and keeping our lab organized. 


\title{
ABSTRACT \\ AGE-ASSOCIATED CHANGES IN INNATE IMMUNITY AND THEIR IMPACTS ON INFLAMMATORY DISEASES
}

\author{
Mehmet Akif Eskan DDS
}

November 3, 2011

Periodontal disease arises from excessive host inflammatory responses to the tooth-associated microbial biofilm, known as dental plaque. Severity ranges from superficial inflammation of the gingivae (gingivitis) to extensive destruction of connective tissue and bone (periodontitis) leading to tooth loss. In its severe form, periodontitis affects $10-15 \%$ of the total human population to the extent that they will lose half their teeth by age 50 . Periodontitis, a prevalent chronic disease with an impact on systemic health, such as atherosclerosis and Alzheimer's disease, is critically dependent on neutrophils. Although conventional periodontal treatment may reverse destructive inflammation, a subset of patients develops recurrent disease for reasons that are not clear, thus necessitating better understanding of the underlying immunopathology. Therefore, there is a compelling need to elucidate pathogenic mechanisms, which may be targeted for novel therapeutic intervention strategies in periodontal disease.

Developmental endothelial locus-1 (Del-1) was recently identified as a novel endothelial-derived inhibitor of neutrophil extravasation. However, whether 
Del-1 regulates the local tissue-specific inflammatory response and controls chronic inflammatory diseases has not been addressed yet. Upon aging, normal mice displayed increased disease accompanied by diminished Del-1 expression. Consistent with a protective role for Del-1 in periodontitis, $\mathrm{Del}-\mathrm{1}^{-/}$mice developed spontaneous inflammatory periodontal bone loss characterized by excessive local neutrophil infiltration and interleukin (IL)-17 expression. The disease was reversed in $\mathrm{Del}-1^{-/-}$mice with additional genetic deficiencies in the LFA-1 integrin or the IL-17 receptor. Strikingly, local administration of Del-1 suppressed neutrophil infiltration and IL-17 expression in the periodontal tissue. We, therefore, concluded that Del-1 is required for tissue homeostasis by regulating LFA-1-dependent neutrophil trafficking, inhibiting IL-17-mediated pathology, and may be a promising novel therapeutic for the treatment of inflammatory diseases.

In conclusion, we showed that Del-1, a novel inhibitor of integrindependent neutrophil adhesion, regulates local tissue-specific inflammation and controls chronic inflammatory disease. Del-1 inhibits LFA-1-dependent neutrophil recruitment and IL-17-mediated pathology and may be a promising novel therapeutic for inflammatory diseases. 


\section{TABLE OF CONTENTS}

\section{PAGE}

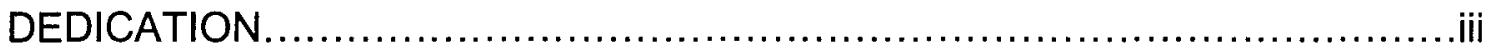

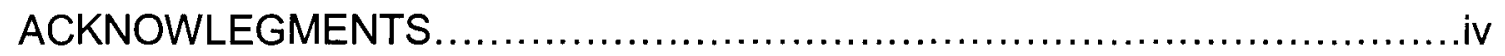

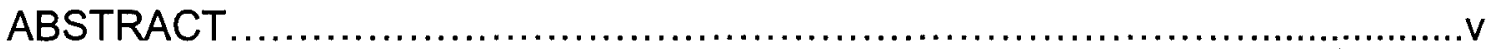

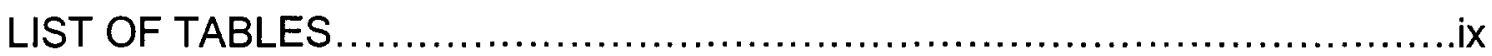

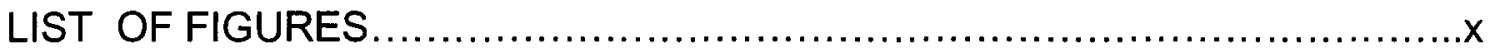

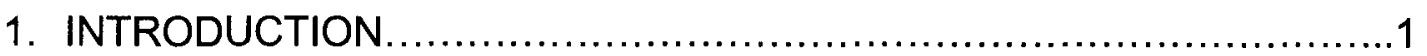

- Aging and Inflammation...............................................

- Neutrophils and IL-17A ..............................................

- Del-1 and Neutrophils................................................

• Significance.....................................................................

2. MATERIALS AND METHODS .............................................18

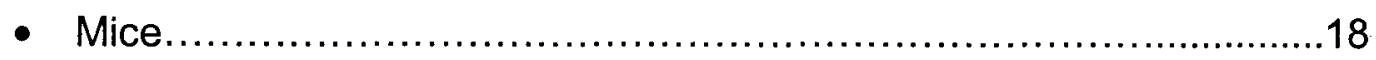

- Determination of periodontal bone loss.....................................18

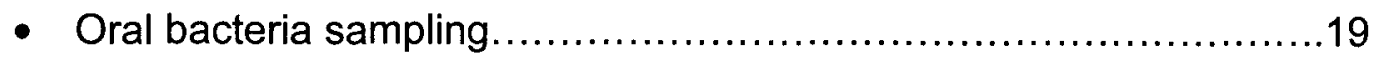


- Quantitative real-time PCR ...........................................19

- Immunohistochemistry.................................................. 19

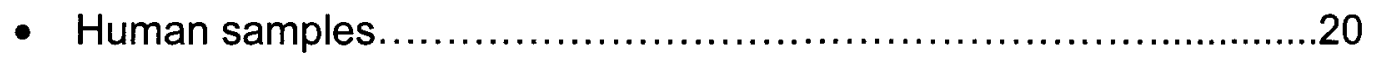

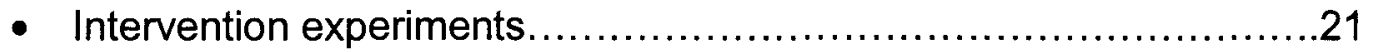

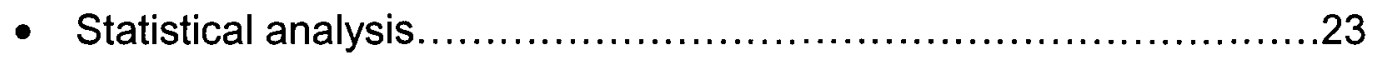

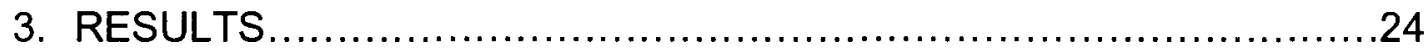

- Aged mice show decreased Del-1 expression which correlates with

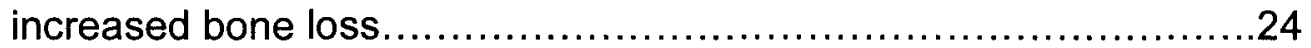

- Del-1 ${ }^{-1-}$ mice exhibit enhanced inflammation and bone loss.............32

- Inflammatory bone loss in Del-1 deficiency requires LFA-1 function and

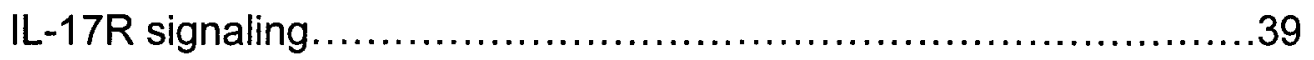

- IL-17 regulates Del-1 expression as a function of age.................47

- Local administration of soluble Del-1 reverses periodontal inflammation

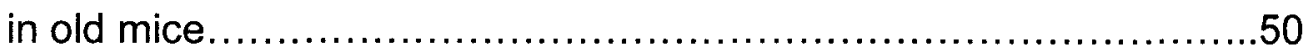

- Del-1 expression is reduced in human with periodontitis................55

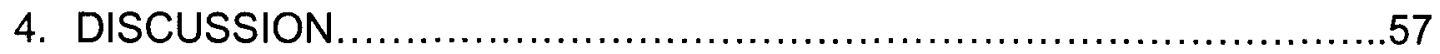

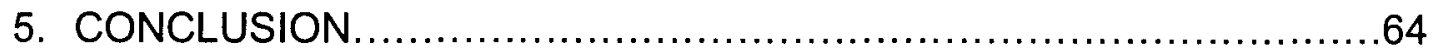

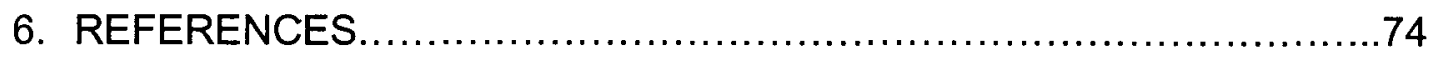

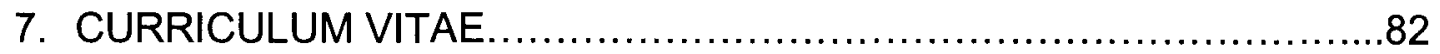




\section{LIST OF TABLES}

TABLE

PAGE

1. Some important molecules that play important role in neutrophil and IL-17 mediated tissue destruction............................................12

2. Reduced mRNA levels of inflammatory mediators in the gingiva of aged mice after local administration of soluble Del-1 .........................53 


\section{LIST OF FIGURES}

Figure

PAGE

1. The percentage of elderly is increasing in USA .........................

2. Homology of IL-17 family members to IL-17A $\ldots \ldots \ldots \ldots \ldots \ldots \ldots \ldots . . . \ldots$

3. Neutrophil transmigration through endothelial cells...................11

4. The interaction between Del-1 and LFA-1 ...........................14

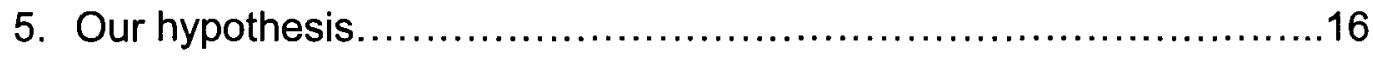

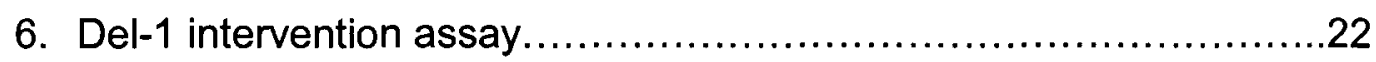

7. Del-1 is expressed in the mouse gingiva.............................26

8. Reduced expression of Del-1 in old mice correlates with periodontal bone loss

9. Reduced expression of Del-1 in old mice correlates with increased number iof neutrophils .28

10. IL-17 expression is increased in old mice. .29

11. Reduced expression of Del-1 in old mice correlates with periodontal bone loss. .31

12. Del-1 deficiency is associated with inflammatory bone loss 33 
13. Del-1 deficiency is associated with inflammatory response in the periodontium

14. Increased recruitment of neutrophils and expression of IL-17 in the gingiva of $\mathrm{Del}-1^{-/ /}$mice .36

15. Del-1 deficiency is associated with elevated numbers of bacteria in the periodontium. .38

16. Increased bone loss and neutrophil number in Del- ${ }^{-1}$ is reversed in mice with dual Del-1/LFA-1 deficiency.

17. Del-1 deficiency-associated inflammatory response is reversed in mice with dual Del-1/LFA-1 deficiency.

18. Del-1 deficiency-associated inflammatory bone loss is reversed in mice with dual Del-1/LFA-1 or Del-1/L-17R deficiencies. .44

19. Del-1 deficiency-associated bone loss is reversed in mice with dual Del-1/LFA-1 or Del-1/L-17R deficiencies 45

20. Bone loss in different genotype comparable periodontal bone levels in early-age mice regardless of genotype 46

21. Del-1 expression is downregulated by IL-17 in old SPF mice...........48

22. Del-1 treatment reverses periodontal inflammation in old mice. .51

23. Expression of IL-17 and Del-1 in human gingival....................56

24. A domain structure of Del-1. .72 


\section{INTRODUCTION}

\section{Aging and Inflammation}

The elderly population is increasing. According to the US Bureau of the Census, in 1997, 1 in 8 Americans were over 65 years old and it is expected that 1 in 5 Americans will be elderly by 2030 (Figure 1). Age is usually considered as a risk factor for increased inflammation and impaired wound healing [1]. Physiological loss of periodontal attachment and alveolar bone is seen in the elderly and is normally of little clinical significance. However, these changes can become severe in the presence of concomitant periodontal inflammation as an individual ages [2, 3]. This is consistent with the inflammatory etiology of periodontal disease, where tissue damage is primarily caused by excessive host inflammatory reactions to subgingival gram-negative anaerobic pathogens [4]. Conversely, it may be argued that the increased severity of periodontitis in old age could be simply the cumulative effect of prolonged exposure to microbial challenge. While this might be a contributory factor, several observations support the significance of age-related alterations in the periodontal immune

response. In an experimental gingivitis study involving young (20-25 years of age) and elderly ( $\geq 65$ years) individuals, all subjects received professional dental care to establish healthy gingival starting conditions and, subsequently, abstained from oral hygiene. Although young and old subjects displayed 
comparable dental plaque biofilm accumulation, the latter group developed more severe gingivitis associated with elevated numbers of inflammatory cells [5] indicating that the periodontal innate immune response is influenced by age. 


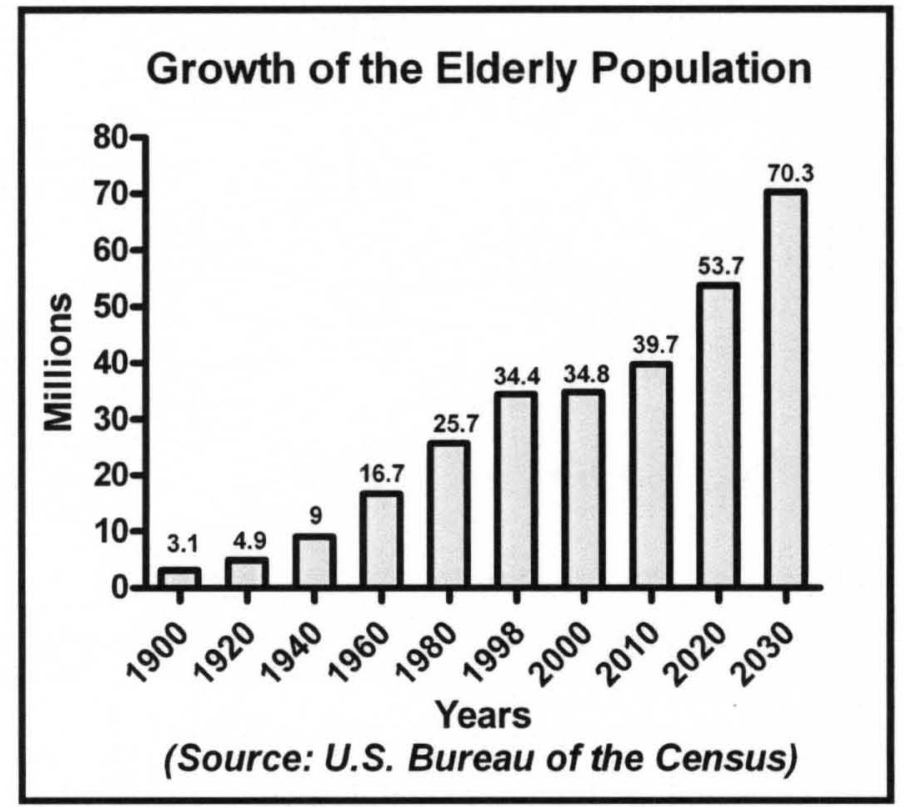

Figure 1. The percentage of elderly is increasing in USA. This shows that the elderly population is increasing in USA. 
The elderly are at increased risk for microbial infection leading to chronic inflammation and malignancy $[6,7]$. Individuals are not equally affected by the accumulation of bacterial plaque around their teeth. Very susceptible subjects will develop aggressive forms of periodontitis at a relatively young age whereas others may never develop periodontitis [8]. Most of the population fall somewhere between these extremes. This might be explained by that monocytes that were carrying different human leukocyte antigen (HLA) harvested from different subjects. Those monocytes responded differently to LPS stimulation with production of pro-inflammatory cytokines, including interlukin 1, tumor necrosis factor alpha or prostaglandin E2, supporting a genetically determined basis for inflammatory disorders [9]. Shapira et al. [10] suggested that interindividual differences in monocyte/macrophage responses can be found in periodontitis patients compared to healthy subjects $[10,11]$. As humans age, they encounter more disease and most of these diseases are due to declines of cellular function, affecting all cell types to different extents. Impaired wound healing in the elderly presents a major clinical and economic problem. With the aging population growing in both number and percentage, the importance of understanding the mechanisms underlying age-related impairments in healing increases. Normal periodontal tissues exhibit characteristic changes with age that have implications for wound healing [12]. It also has been reported that periodontal attachment loss and gingival recession showed an increase by age $[13,14]$. All together, efficient cell function enhances wound healing and limits 
chronic disease and any functional decline in these processes are important health concerns for the elderly.

More than three decades ago, Page and Schroeder reported that polymorphonuclear neutrophils (PMNs) play an important role in periodontal disease progression [15]. It has been consistently reported that periodontally diseased gingiva are abundant with primed and hyperactivated neutrophils releasing oxygen radicals, cytokines and chemokines [16]. Neutrophils might play an important role during the transition from gingivitis to periodontitis. In fact, the concept of a primed or hyperactive neutrophil in chronic $[17,18]$ or aggressive periodontitis [19] has begun to emerge, leading to a new perspective on the role of neutrohils in periodontitis. They are considered scavenging phagocytes, which clear microbes, play a major role in the control of infections by intracellular pathogens and modulate the immune system [20]. In addition to neutrophils, for example, interleukin-17 (IL-17) has been reported to be involved in chronic inflammatory diseases $[21,22]$. 


\section{Neutrophils and IL-17}

Recently, it has been shown that interleukin-17 (also known as IL-17A) is a key cytokine regulating the infiltration of neutrophils into tissues [23]. Specifically, IL-17A has been reported to regulate neutrophil mobilization by promoting granulopoiesis, $[24,25]$. Moreover, IL-17 has been shown to orchestrates activation of neutrophils during inflammation $[26,27]$. IL-17 was also shown to induce the activations and survival of neutrophils [26-28].

The interleukin-17 (IL-17) family, IL-17A to IL-17F, is emerging as major players in immune responses and inflammatory diseases [29]. These cytokines mediate their biological functions through the IL-17 receptor family, IL-17RA to IL-17RE [30]. $50 \%$ of the IL-17A and IL-17F structure is identical (Figure 2), accounting for their sharing several biological properties [30]. It has been well documented that several cell types, such as $\mathrm{T}$ cells, neutrophils, and macrophages, express IL-17A and IL-17F [22, 30, 31]. Tissue mediated innate immunity can be promoted by $\mathrm{IL}-17 \mathrm{~A}$ and $\mathrm{IL}-17 \mathrm{~F}$ by inducing pro-inflammatory responses. IL-17 target molecules include chemokines (CXCL1, CXCL8, CXCL10), cytokines (TNF-a, IL-1, IL-6, and GM-CSF) and acute/delayed-phase responses (RANKL) [24]. Furthermore, it has been reported that the combined action of IL-17A or IL-17F with other cytokines including, TNF- $\alpha$, IL-1 $\beta$ and IFN-Y synergistically augments the induction of pro-inflammatory responses $[32,33]$. Consistently, IL-17A has been implicated in bone resorption in mouse models of arthritis [34] and the absence of IL-17A expression reduced disease activity in rheumatoid arthritis $[22,35]$. Parallel to these studies, neutrophils and IL-17A 
interaction has been reported to induce myocarditis and/or myocardial infarction following experimental bacteremia of Porphyromonas gingivalis in mice [36]. Together, it is becoming clear that there is a strong interaction between IL-17 and neutrophil function. 


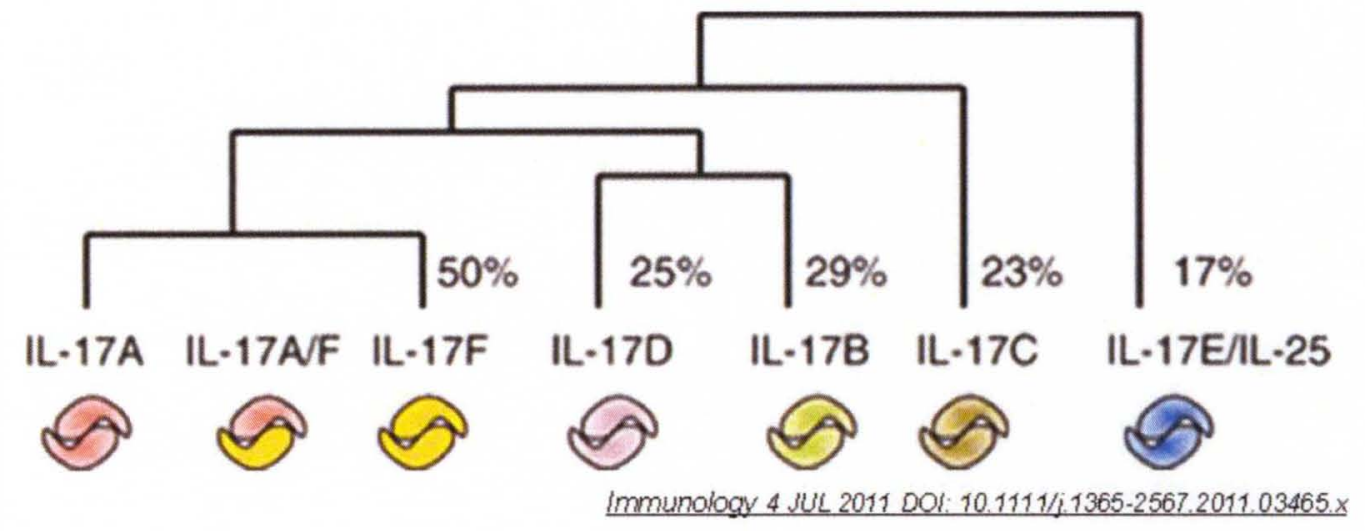

Figure 2. Homology of IL-17 family members to IL-17A. This diagram shows the percentage homology between IL-17A and each of the IL-17 family members. IL17A shares greater homology with IL-17F, while other family members are more divergent. Percentages reflect both human and mouse IL-17 family members. 


\section{Del-1 and Neutrophils}

In response to tissue infection, leukocytes extravasate into peripheral tissues and attempt to kill pathogenic microorganisms. In this regard, and in the context of periodontitis, PMNs form a first line of defense and promptly migrate to the gingival crevice in response to the tooth-associated pathogenic biofilm [37]. PMNs attempt to kill the invading microbes by releasing the toxic contents of their granules including reactive oxygen species (ROS) and reactive nitrogen species, proteinase 3, cathepsin- $G$ and elastase [38]. These highly potent effectors do not discriminate between microbial and host cells, and may result in collateral damage to the host tissues [39]. Because neutrophils display a large array of microbicidal and proinflammatory mechanisms that are potentially harmful to the host, their activation and trafficking is tightly regulated [40-43]. Therefore, tight regulation of PMN recruitment is important for preventing excessive influx and unwarranted inflammation. Inflammatory cell recruitment happens in the three steps involving rolling, activation and adhesion [44]. PMN recruitment to inflamed tissue is regulated by selectins that facilitate cell rolling and activation of $\beta_{2}$ integrins (CD11/CD18) which in turn mediate stable adhesion and migration across the blood vessel [45]. A transition from rolling to arrest involves a shift in $\beta_{2}$ integrins from a low- to high-affinity state which allows it to bind intracellular adhesion molecule-1 (ICAM-1) on endothelial cells (Figure 3) [46]. Following the arresting step, the leukocyte function associated antigen-1 (LFA-1, also known as $\alpha \mathrm{L} \beta 2$ or $C D 11 \mathrm{a} / \mathrm{CD} 18)[47,48]$ plays a critical role for the neutrophil migration into injured tissue [49]. ICAM-1 can adhere with ringlike cluster of LFA-1 cluster 
during neutrophil transmigration [44]. Therefore, the neutrophil transmigration across inflamed endothelium is controlled through LFA-1 interactions with ICAM$1[49,50]$. In addition to these molecules, Table 1 shows some other molecules that play an important role for neutrophil and or IL-17 mediated tissue destruction. 


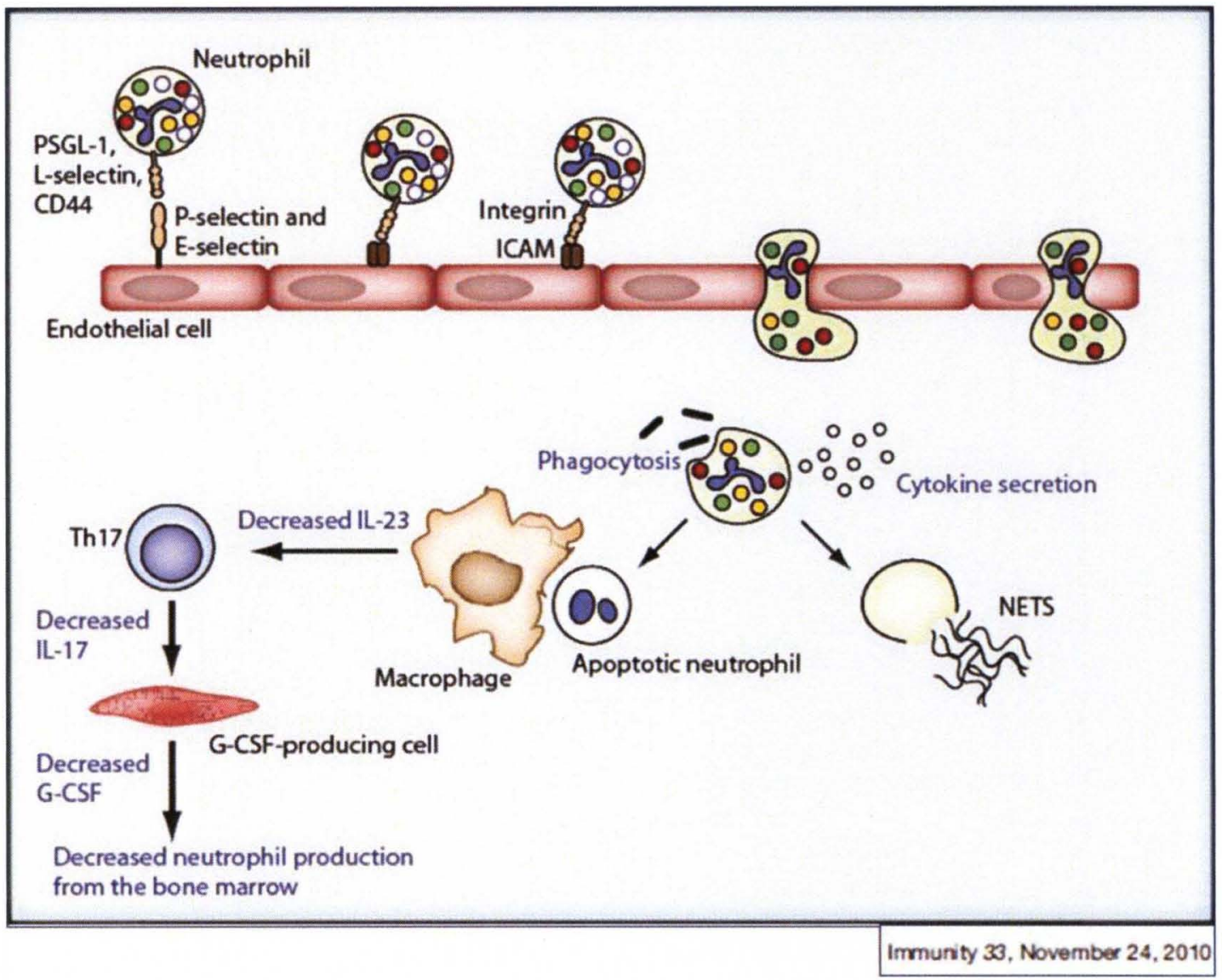

Figure 3. Neutrophil transmigration through endothelial cells. P-selectins play a major role to capture neutrophils, whereas ICAM-1 plays a critical role for their transmigration. After the neutrophils phagocytose microorganisms and degranulate, they may either undergo apoptosis or necrosis. Uptake of apoptotic neutrophils by macrophages downmodulates the production of IL-23, leading to downregulation of IL-17 production. 


\begin{tabular}{|c|c|c|}
\hline Gene & Function & Ref \\
\hline Ly6G & Defines neutrophils & [51] \\
\hline ICAM-1 & Plays a critical role in the neutrophil recruitment & {$[48,49]$} \\
\hline $\begin{array}{l}\text { LFA-1 } \\
\text { (CD11a/ldgal) }\end{array}$ & Plays a critical role in the neutrophil recruitment & {$[48,49]$} \\
\hline Del-1 & $\begin{array}{l}\text { Inhibits LFA-1-ICAM-1 interactions and limits neutrophil migration to sites } \\
\text { of infection/inflammation }\end{array}$ & [52] \\
\hline CD62E & Increases LFA-1 affinity to ICAM-1 & [53] \\
\hline $\mathrm{KC}(\mathrm{CXCL1})$ & Involved in neutrophil chemotaxis & {$[54,55]$} \\
\hline $\mathrm{CCL} 2$ & $\begin{array}{l}\text { Chemokine produced by neutrophils; induces Th17 migration to sites of } \\
\text { inflammation }\end{array}$ & $\begin{array}{ll}{[56,} & 57],[ \\
58] & \end{array}$ \\
\hline CCL20 & $\begin{array}{l}\text { Chemokine produced by neutrophils; induces Th17 migration to sites of } \\
\text { inflammation }\end{array}$ & [58-61] \\
\hline CCR2 & Chemokine receptor (responds to CCL2); mediates Th17 recruitment & $\begin{array}{l}{[57, \quad 58,} \\
62]\end{array}$ \\
\hline CCR6 & Chemokine receptor (responds to CCL20); mediates Th17 recruitment & $\begin{array}{l}{[57,58,} \\
61,63]\end{array}$ \\
\hline RORyt & $\begin{array}{l}\text { Transcription factor; required for Th17 cell differentiation; defines Th17 } \\
\text { cells }\end{array}$ & [64] \\
\hline IL-6 & Promotes Th17 cell differentiation & [65] \\
\hline TGF- $\beta$ & Promotes Th17 cell differentiation & [65] \\
\hline IL-21 & Produced by Th17; induces and amplifies Th17 in cooperation with TGF- $\beta$ & [66] \\
\hline IL-22 & Produced by Th17 cells in response to IL-23 & [67] \\
\hline IL-23 & Stabilizes the commitment of developing Th17 cells to the Th17 lineage & {$[65,68]$} \\
\hline IL-17A & Control of extracellular pathogens, induction of matrix destruction & {$[69,70]$} \\
\hline TNF- $a$ & Major effector of periodontal bone loss & [71] \\
\hline IL-1 $\beta$ & Major effector of periodontal bone loss & [71] \\
\hline
\end{tabular}

Table 1. Some other important molecules that play important role in neutrophil and IL-17 mediated tissue destruction. 
Since circulating neutrophils readily migrate to sites of extravascular infection or inflammation to eliminate or control pathogenic insults, the extravasation of neutrophils is critically dependent on a series of well-coordinated adhesive events, as we discussed above, including the interactions of integrins of the $\beta 2$ or $\beta 1$ family with endothelial countereceptors of the Ig superfamily [40, 43]. In contrast to multiple factors promoting leukocyte extravasation, little is known about inhibitors of the leukocyte adhesion cascade. In this context, a 52-kDa glycoprotein, known as developmental endothelial locus-1 (Del-1), was recently identified as a novel negative regulator of neutrophil extravasation acting by antagonizing the interaction between ICAM-1 and LFA-1 (Figure 4) [52]. It also has been shown that Del-1 induced engulfment of apoptotic cells [72]. Pentraxin 3 (PTX3) is another recently identified inhibitor of neutrophil extravasation, which acts by suppressing selectin-dependent rolling [73]. In contrast to PTX3, however, Del-1 is produced by the tissue rather than the inflammatory cell itself $[52,73]$. Specifically, Del-1 is secreted by endothelial cells and may associate with the endothelial cell surface and the extracellular matrix $[43,62]$. This observation predicts that Del- 1 could play a critical role in regulating the local chronic inflammatory response in tissues expressing it; however this hypothesis has not been addressed so far. 


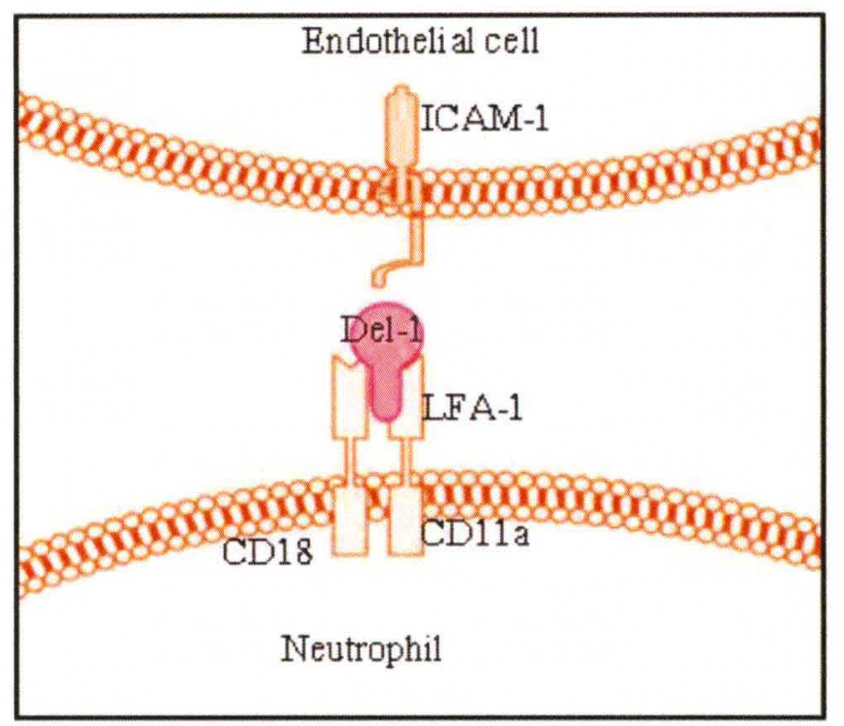

Figure 4. The interaction between Del-1 and LFA-1. Del-1 inhibits the interaction between ICAM-1 and LFA-1 by binding CD11a. 
We reasoned that Del-1 may provide a mechanism whereby a tissue itself may control or prevent persistent inflammation associated with chronic recruitment of neutrophils. As we discussed above, periodontitis is a chronic inflammatory disease and neutrophils modulate its progression [15]. Therefore, periodontitis represents an attractive model to determine the role of Del-1 in neutrophil-mediated chronic inflammation with impact on systemic diseases. Old age and age-associated inflammation are factors that contribute to increased prevalence and severity of periodontitis in humans and mice [74, 75]. Our overall hypothesis is that age-associated reductions in Del-1 expression leads to excessive recruitment of neutrophils and increased IL-17A production in periodontal tissues, resulting in enhanced periodontal inflammation and periodontal bone loss. (Figure 5). This hypothesis constitutes a novel mechanism for the increased periodontal tissue destruction seen in the elderly. 


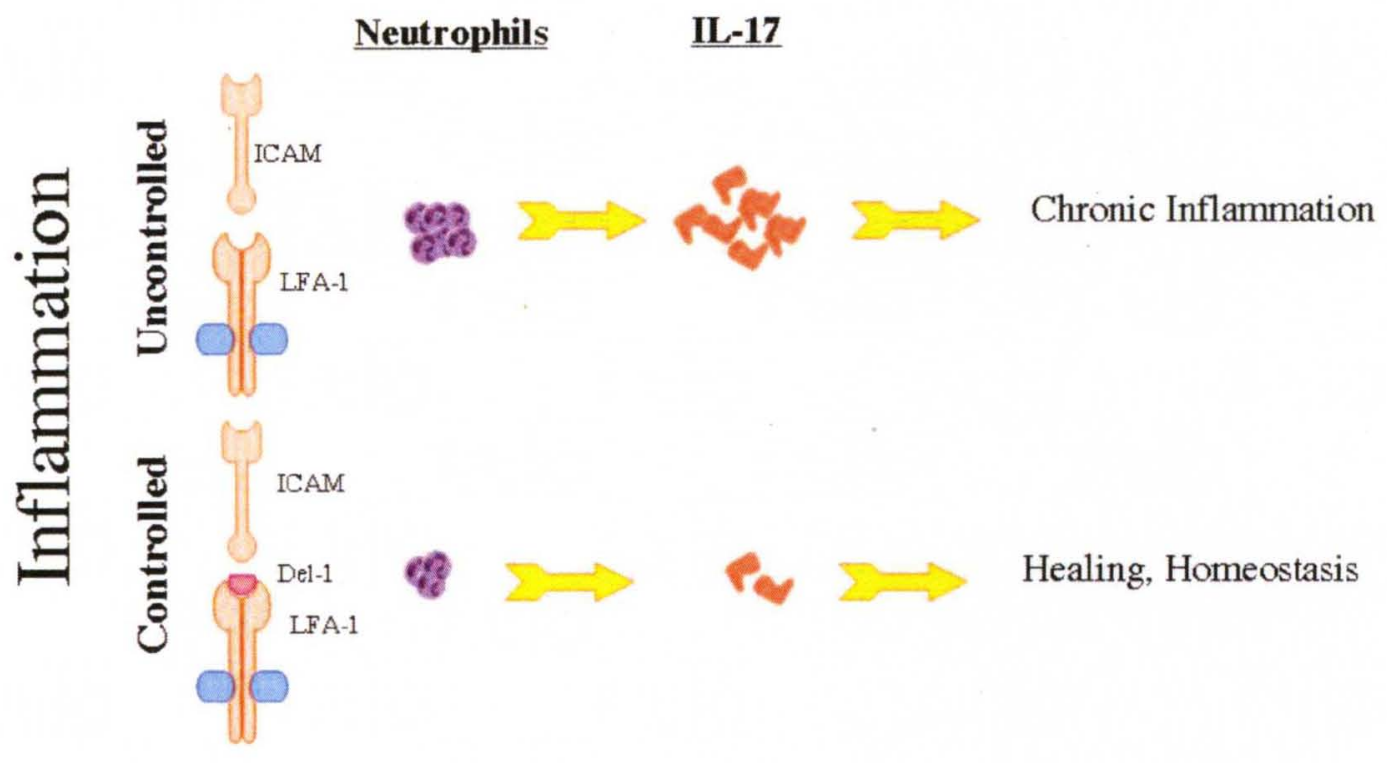

Figure 5. Our hypothesis. Uncontrolled neutrophil accumulation due to reduced Del-1 expression results in increased IL-17, leading to chronic inflammation. 
Significance: Our proposed experiments are expected to reveal novel mechanisms of periodontal pathogenesis and pave the way for Del-1-based therapeutic intervention in periodontitis. On the basis of our hypothesis that Del1 expression decreases with aging, Del-1-based therapy could be extremely beneficial to elderly patients who run a higher risk for periodontitis [5]. Del-1based control of periodontal disease can also decrease the risk for systemic inflammatory diseases, like atherosclerotic heart disease, which is epidemiologically and mechanistically linked to periodontitis $[37,76,77]$. 


\section{MATERIALS AND METHODS}

Mice. All mice used were on C57BL/6 background. IL-17RA $A^{-1-}$ and $L F A-1^{-1-}$ mice were generously provided, respectively, by Amgen (Seattle, WA)[78] and Dr. C.M. Ballantyne (Baylor College of Medicine) [79]. The generation of Del-1/.

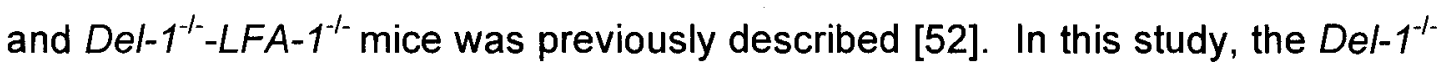
and IL-17RA ${ }^{-l-}$ mice were crossed to generate double knock-outs (Del-1-1- $/ L$ $17 R A^{-1}$ ). Old C57BL/6 mice (18 months of age) were obtained from the National Institute of Aging. In aging experiments to investigate the effect of Del-1 deficiency, knockout mice and wild-type littermate controls were reared in parallel under specific-pathogen-free conditions in individually ventilated cages in the Barrier Animal Facility of the University of Louisville. All animal procedures described in this study were approved by the Institutional Animal Care and Use Committee, in compliance with established federal and state policies.

Determination of periodontal bone loss. Periodontal bone levels were assessed in defleshed maxillae under a dissecting microscope (x40) fitted with a video image marker measurement system (VIA-170K; Boeckeler Instruments) standardized for measurements in millimeters. Specifically, the distance from the cementoenamel junction (CEJ) to the alveolar bone crest $(A B C)$ was measured on 14 predetermined points on the buccal surfaces of the maxillary molars [80, 81]. To calculate relative bone loss (e.g., Del-1 $1^{-1-}$ mice vs. wild-type controls, or 
old mice vs. young controls), the 14-site total CEJ-ABC distance for each mouse was subtracted from the mean CEJ-ABC distance of control mice. The results were expressed in $\mathrm{mm}$ and negative values indicated bone loss relative to controls $[80,81]$. In certain experiments, bone loss was measured in mice which were administered antibiotics in their drinking water (sulfamethoxazole and trimethoprim at a final concentration of $800 \mu \mathrm{g} / \mathrm{ml}$ and $400 \mu \mathrm{g} / \mathrm{ml}$, respectively).

Oral bacterial sampling. To assess the oral microbial burden, the murine oral cavity was sampled for 15 seconds using sterile paperpoints held against the gumlines [81]. Serial dilutions of the paperpoint extracts were plated onto blood agar plates for anaerobic growth and CFU determination.

Quantitative real-time PCR. Gingival tissue was excised from around the maxillary molars. Total RNA was extracted by using the PerfectPure RNA cell kit (5 Prime, Fisher) and quantified by spectrometry at 260 and $280 \mathrm{~nm}$. The RNA was reverse-transcribed using the High-Capacity cDNA Archive kit (Applied Biosystems) and quantitative real-time PCR with CDNA was performed using the $\mathrm{ABI} 7500$ Fast System, according to the manufacturer's protocol (Applied Biosystems). TaqMan probes, sense primers, and antisense primers for expression of genes examined in this study (Figures 13 and Table 2), or a housekeeping gene (GAPDH), were purchased from Applied Biosystems.

Immunohistochemistry. Upper jaws (maxillae) with intact surrounding tissue were fixed in $4 \%$ paraformaldehyde, decalcified in Immunocal Solution (Decal Chemical Corp.) for 15 days, and embedded in OCT compound. Serial 
mesio-distal sections (7- to $8-\mu \mathrm{m}$ thick) parallel to the long axis of the teeth (sagittal) were stained with antibodies to human/mouse Del-1 (Proteintech), mouse Ly6G, a specific neutrophil marker [51] (FITC-conjugate; LifeSpan BioSciences), human/mouse IL-17A (Santa Cruz Biotech), and human/mouse TNFa (Abcam). The antibodies to Del-1, IL-17A, and TNF $\alpha$ were rabbit IgG and staining involved the use of a secondary reagent (Texas red-goat anti-rabbit lgG; Molecular Probes). The specificity of staining was confirmed by using FITCconjugated isotype control (rat IgG2b) or normal rabbit lgG followed by Texas red-conjugated goat anti-Rabbit IgG. Images were captured using a laserscanning confocal microscope (Olympus FV1000). Fluorescence intensity was quantified using the Image J software (NIH; http://rsb.info.nih.gov/ii).

Human samples. Under IRB approval, samples were collected from patients undergoing periodontal surgery at the graduate periodontics clinic. Diseased tissues were usually collected around involved tooth. Healthy tissues were usually collected from the distal of last molar teeth in maxilla. Diseased sites were determined if attachment loss was more than $5 \mathrm{~mm}$ and/or bleeding on probing. Excised tissues, nature of periodontal surgery, kept on $10 \%$ of formalin for future staining of Del-1 and/or IL-17A. Gingival tissue samples were incubated with $10 \%$ paraformaldehyde at $4^{\circ} \mathrm{C}$ and washed with $5 \%, 10 \%$, and $15 \%$ glycerol for 15 minutes. The tissues were immersed in $30 \%$ sucrose for 30 min and embedded in a medium for frozen tissues (Tissue-Tek) for cryostat sectioning $(10 \mu \mathrm{m})$. Samples were blocked with $10 \%$ BSA (Millipore) at room temperature for 1 hour, incubated with anti-mouse/human Del-1 (1/100, 
Proteintech) or IL-17A (1/100 Santa Cruz) overnight at $4^{\circ} \mathrm{C}$. Following washing three times with cold PBS, samples were stained with Texas red conjugated antirabbit IgG (1/1000, Invitrogen) or FITC-conjugated donkey anti-goat IgG (1/200, Santa Cruz) for 1 hour at room temperature. The sections were mounted (Vector) after washing three times with cold PBS. Subsequently, pictures of the stained tissue sections were captured using a Confocal microscope (Olympus, V500).

Intervention experiments. Ten 18-month-old C5BL/6 mice were microinjected in the gingiva with soluble recombinant mouse Del-1 (kindly provided by Valentis, Inc.) [52] and another ten mice with BSA control. Specifically, Del-1 or BSA (1 $\mu \mathrm{g}$ in $1-\mu$ l volume) were microinjected through a 28.5-gauge MicroFine needle (BD) into the palatal gingiva between the first and the second molar teeth, on both sides of the maxilla (Figure 6). Half of the Del-1or BSA-treated mice were additionally orally inoculated with $P$. gingivalis ATCC $33277\left(10^{9} \mathrm{CFU}\right)$ in $2 \%$ carboxymethylcellulose vehicle and the other half were orally given vehicle only. To determine whether IL-17 regulates Del-1 expression in old mice, a neutralizing anti-IL-17 mAb (clone M210, rat IgG2a, kindly provided by Amgen) or $1 \mu \mathrm{g}$ of azide-free rat IgG2a (Biolegend), served as a control, were microinjected into interdental papilla between $1^{\text {st }}$ and $2^{\text {nd }}$ molar from palatal side. All mice were sacrificed $12 \mathrm{~h}$ later. Maxillae were harvested and one side was stored in $4 \%$ paraformaldehyde (for immunohistochemistry; see above) while the other side was used to dissect interdental gingiva (between first and second molar teeth), which were placed into RNA-later solution (Ambion) for quantitative real-time PCR (see above). 


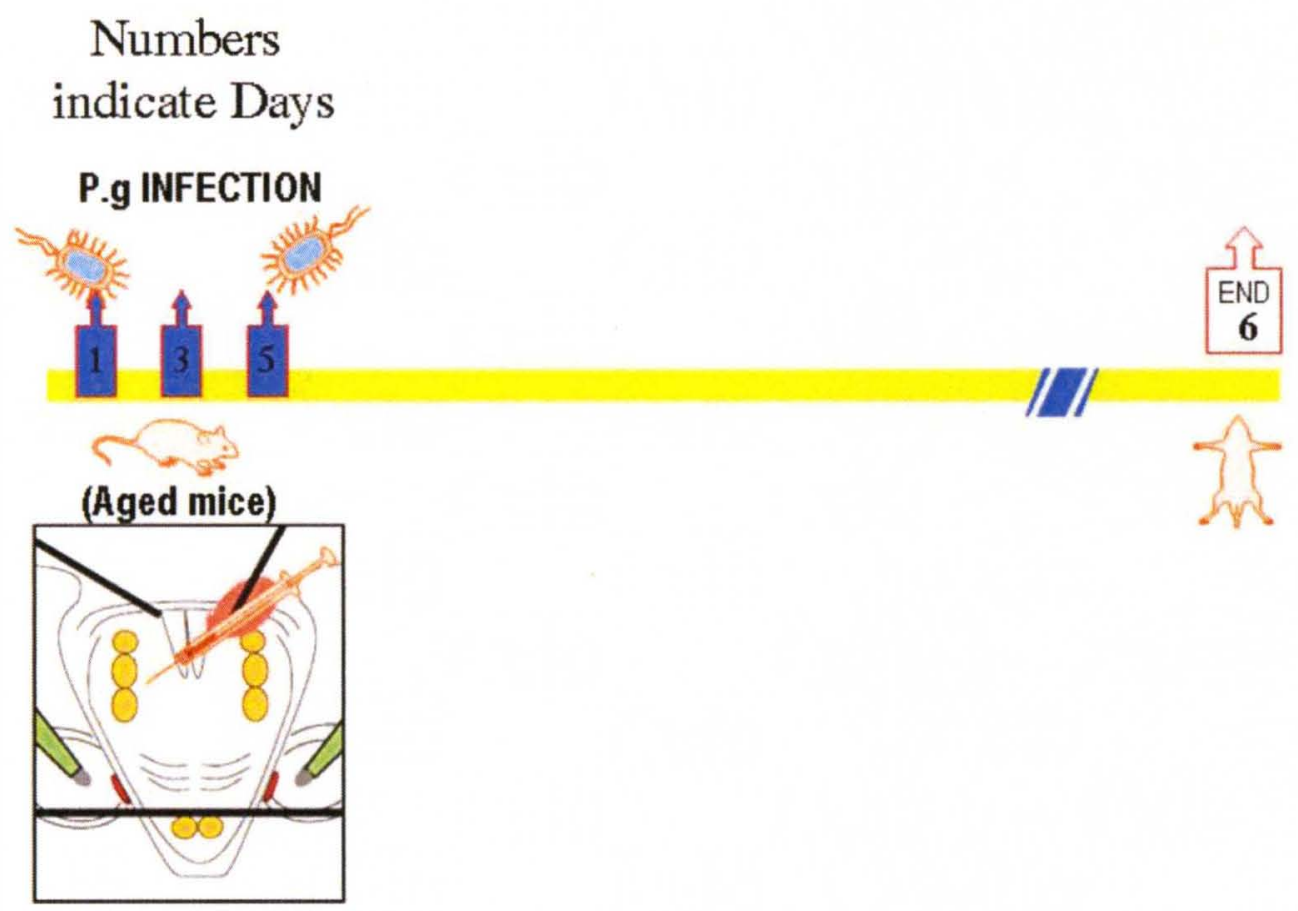

Figure 6. Del-1 intervention assay. Del-1-Fc (1 $\mu \mathrm{l}$ of a $10 \mu \mathrm{g} / \mathrm{ml}$ solution) was administered through microinjection (using a 28.5-gauge MicroFine needle; BD) into the palatal gingivae between the first and the second molar, one hour prior to each infection. Control mice were microinjected a similar concentration of bovine serum albumin (BSA). This study, therefore, involved four groups of aged mice (5 animals per group): Sham-infected treated with BSA, Sham-infected treated with Del-1-Fc, $P$. gingivalis-infected treated with BSA, $P$. gingivalis-infected treated with Del-1-Fc. Experimental and control aged mice (5 per group) were microinjected with Del-1-Fc and BSA, respectively, a total of three times every other day. Following each administration of Del-1-Fc or BSA, the mice were also orally infected with $10^{9}$ CFU P. gingivalis 33277 in $2 \%$ carboxymethylcellulose. 
To determine if IL-17 regulates Del-1 expression in old mice, a neutralizing antiIL-17 mAb was microinjected using the method as described above. The mice were euthanized $12 \mathrm{~h}$ after the last infection.

Statistical analysis. Data were evaluated by analysis of variance and the Dunnett multiple-comparison test using the InStat program (GraphPad Software, San Diego, CA). Where appropriate (comparison of two groups only), two-tailed $t$ tests were performed. $p<0.05$ was considered to be significant. All experiments were performed at least twice for verification. 


\section{RESULTS}

\section{Aged mice show decreased Del-1 expression which correlates with increased bone loss.}

Old age is associated with increased susceptibility to chronic inflammatory diseases $[2,82-84]$ several of which, including periodontitis, involve neutrophilmediated tissue injury $[12,16,42,85-87]$. However, none of these diseases have been linked to age-associated alterations in Del- 1 expression, which could be responsible for dysregulated chronic recruitment of neutrophils to affected tissues. Aging mice, like aging humans, can naturally develop periodontal bone loss $[74,84]$. We therefore examined whether age-related mouse periodontitis is associated with changes in Del-1 expression. Given that Del-1 is expressed in select tissues (e.g., brain and lungs but not liver or spleen) [43], we first examined and showed that Del-1 is expressed in the gingival tissue of the periodontium at the mRNA and protein level (Figure 7). Similar to previous findings in $\mathrm{BALB} / \mathrm{C}$ mice [74], C57BL/6 mice (used throughout this study) developed periodontal bone loss in advanced age (Figure 8b). Intriguingly, gingival tissue harvested from 18-month-old mice displayed about 4-fold lower expression of Del-1 mRNA than gingiva from young mice (8- to 10-week old) (Figure $9 b$ ) and a pronounced difference was also noted at the protein level (Figure 9a, upper row). Interestingly, the reduced expression of Del-1 in the 
gingiva of old mice was associated with higher neutrophil infiltration relative to young mice (Figure 9a, lower row). Moreover, we found that periodontal tissue harvested from old mice (>18 months) exhibited about 3-fold more expression of IL-17 than periodontium from young mice (Figure 10). 
A

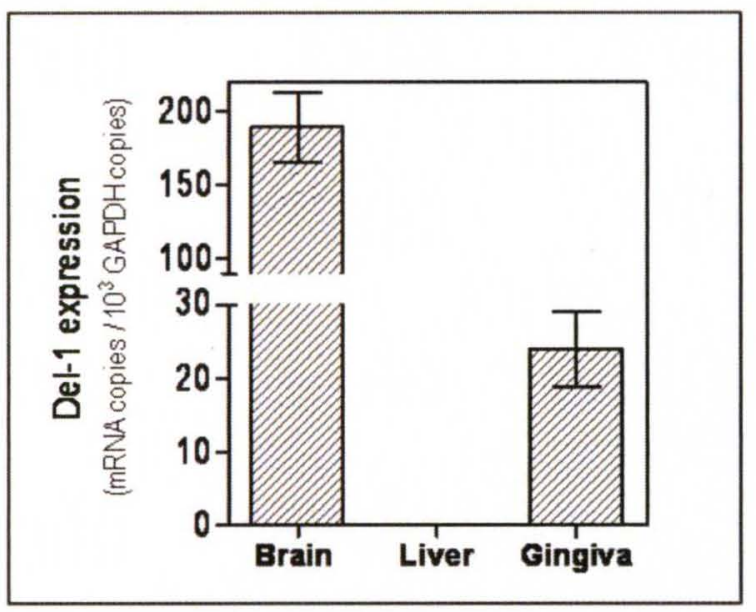

B

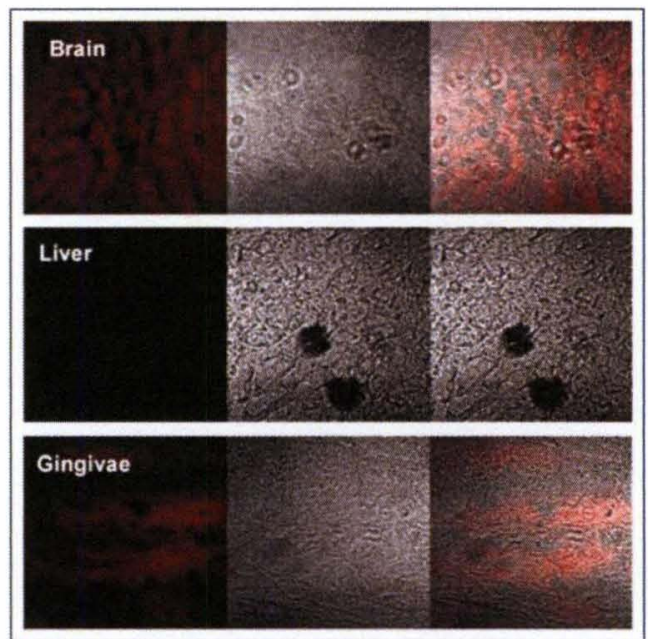

Figure 7. Del-1 is expressed in the mouse gingiva. (a) Brains, livers, and gingiva were harvested from 8-week-old C57BL/6 mice and processed for quantitative real-time PCR to determine Del-1 mRNA levels (normalized against GAPDH mRNA; data are means $\pm \mathrm{SD}, n=3$ mice per group). (b) Brains, livers, and gingiva were stained for Del-1 protein. Brain and liver served as positive and negative controls, respectively, for gingiva. 

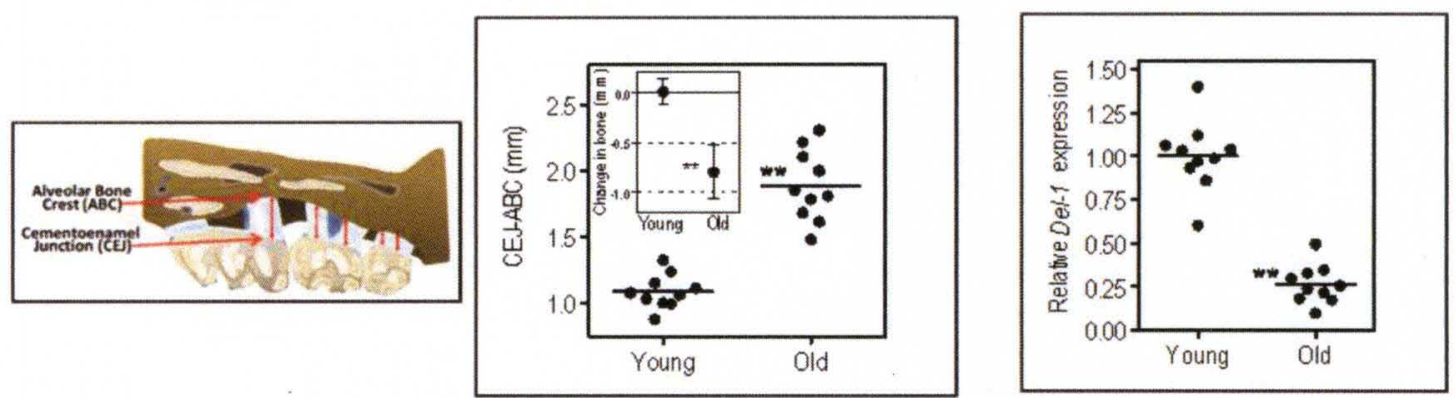

Figure 8. Reduced expression of Del-1 in old mice correlates with periodontal bone loss. (a) Increased bone loss in old C57BL/6 mice (18 months of age) compared to young controls (8-10 weeks), calculated based on measured distances between the cementoenamel junction (CEJ) and the alveolar bone crest (ABC). (b) Gingiva were dissected from the same mice and qPCR was used to determine Del-1 mRNA expression levels (normalized against GAPDH mRNA and expressed as fold change of old relative to young mice, the average value of which was taken as 1 . Data are means $\pm S D ; n=5$ mice per group). ${ }^{* *} p<0.01$ compared to young controls. 
A

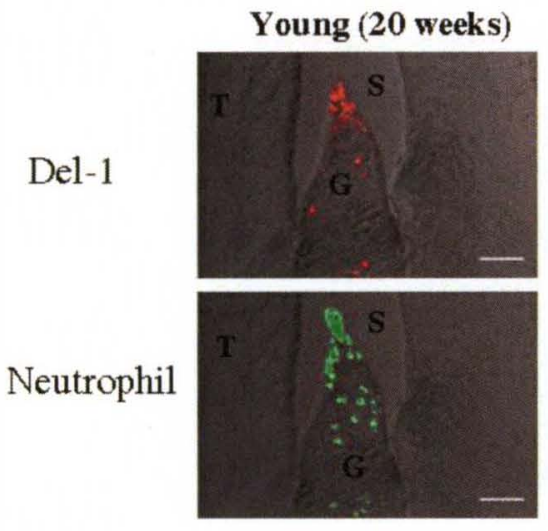

B

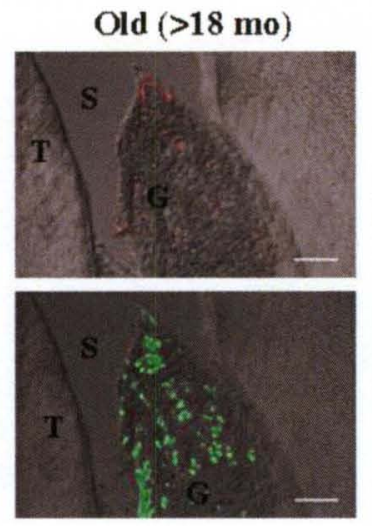

Figure 9. Reduced expression of Del-1 in old mice correlates with increased number of neutrophils. (a) Sagittal sections of interdental gingiva of young (C57BL/6, 20 weeks) and old mice (C57BL/6, 18 months of age) were stained for Del-1 protein (upper left) and the neutrophil-specific marker Ly6G (lower left); shown are representative overlays of differential interference contrast and

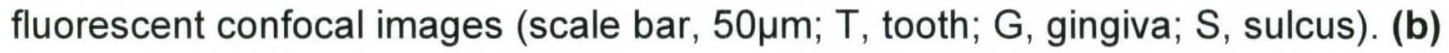
The fluorescence intensities of shown image (a) and of additional representative images from independent mice were quantified using ImageJ analysis (data are means $\pm S D ; n=5$ mice per group). 
A

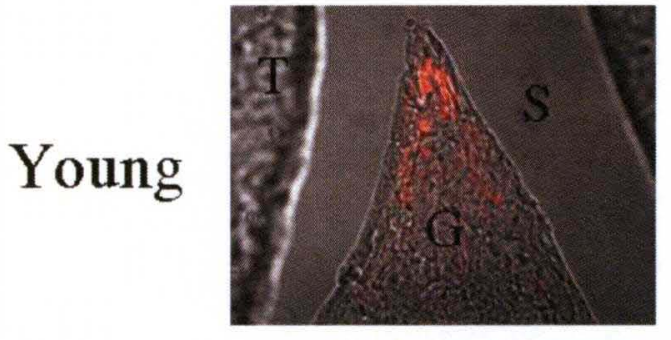

Old

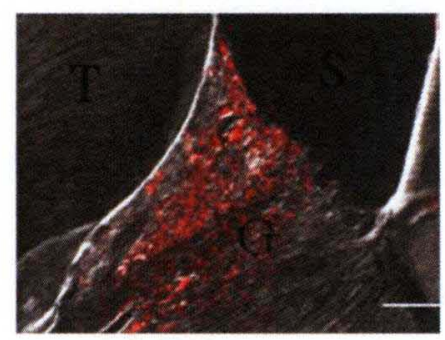

B

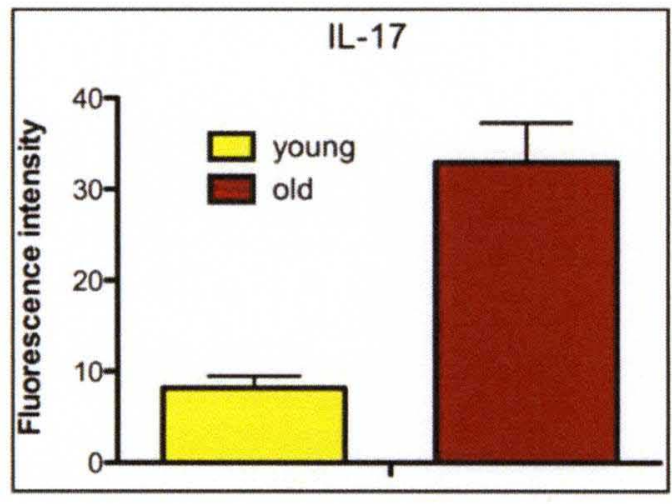

Figure 10. IL-17 expression is increased in old mice. (a) Sagittal sections of interdental gingiva of young and old mice were stained for IL-17. (b) Fluorescence intensity was quantified using ImageJ analysis. Data are means \pm SD ( $n=4$; mice per group). This experiment was repeated three times. 
Figure 8a shows the individual values for the measured distances between the cementoenamel junction (CEJ) and the alveolar bone crest (ABC), which were used to calculate the relative bone loss in old mice (Figure 8b). Linear-regression analysis of the CEJ-ABC values versus Del-1 expression (data from figures 1a and $1 b$, respectively) revealed a significant inverse association between Del-1 expression and periodontal bone loss in old mice (Figure 11a) $\left(r^{2}=0.6254, p=\right.$ 0.0065). This association was also significant, but not as strong, within the young group $\left(r^{2}=0.4641, p=0.0301 ;\right.$ Figure $\left.11 b\right)$. Thus, an inverse relationship between Del-1 expression and bone loss exists not only between young and old mice (Figure $8 \mathrm{~b}$ and $\mathrm{c}$ ), but also within the individual age groups. These data suggest that aging is associated with Del-1 deficiency in the periodontium which may contribute to dysregulated neutrophil recruitment and induction of bone loss. 
A

Old mice

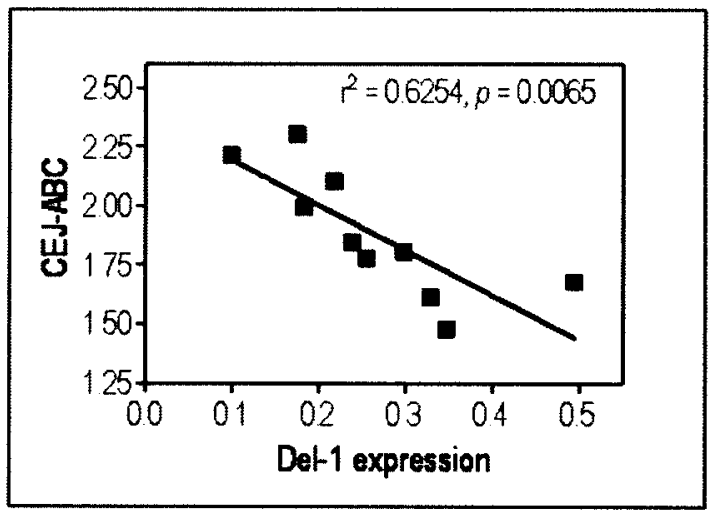

B

Young mice

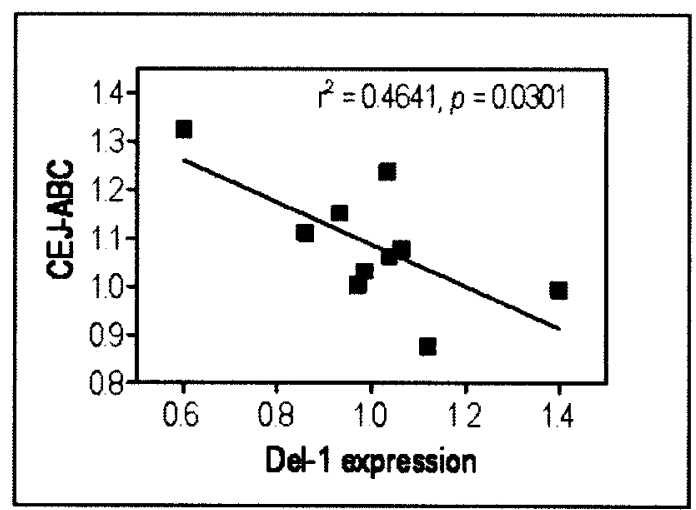

Figure 11. Reduced expression of Del-1 in old mice correlates with periodontal bone loss. Linear-regression analysis of the CEJ-ABC distance values versus Del-1 expression in old (a) and young (b) mice using the data from figure $9 \mathbf{a}$ and $\mathbf{b}$. ( $n=5$ mice per group). 


\section{Del-1/- mice exhibit enhanced inflammation and bone loss}

To determine a direct role for Del-1 in preventing local inflammatory pathology, we investigated the periodontal phenotype of Del- $1^{-1-}$ mice. Sixteenweek-old $\mathrm{Del}-\mathrm{1}^{-1-}$ mice of either gender exhibited significant periodontal bone loss relative to their respective age-matched wild-type controls (Figure 12a). Female and male $\mathrm{Del}-1^{-1-}$ mice had similar susceptibility to periodontitis, and further studies utilized exclusively females. To exclude the possibility that the observed bone loss in 16-week-old Del-1-1/ mice relative to age-matched wild-type controls (Figure 12a) was due to innately different periodontal bone levels, we examined

Del- $1^{-1-}$ and wild-type mice at different ages. At the age of 5 weeks, no difference in the bone levels between $\mathrm{Del}-1^{-1-}$ and wild-type mice was observed, whereas progressive differences were seen with advancing age (Figure 12b). Therefore, the bone loss exhibited by $\mathrm{Del}-\mathrm{1}^{-1-}$ mice is an acquired rather than an innate trait. 
A

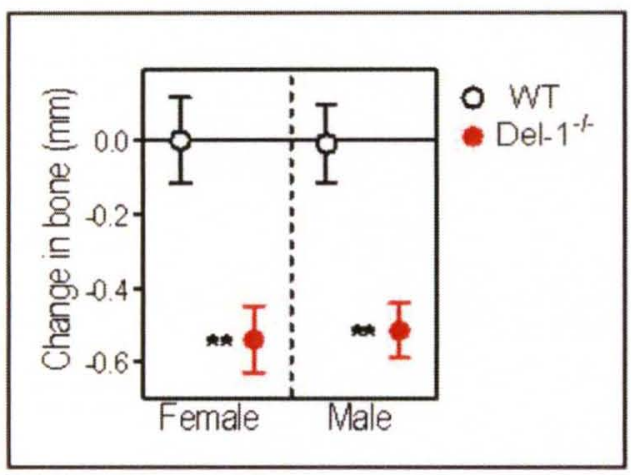

B

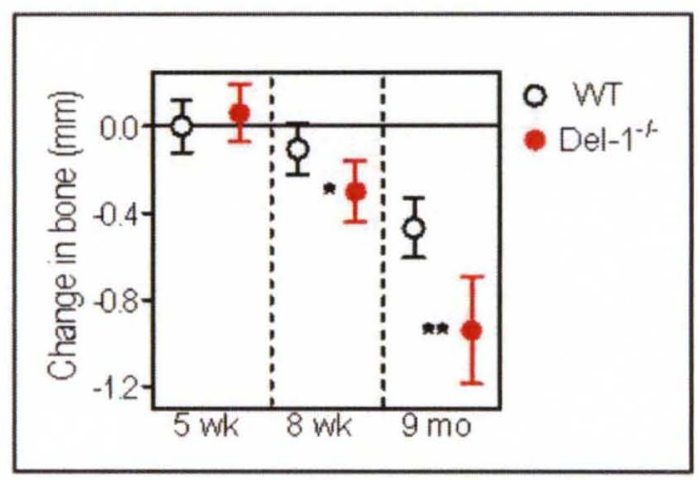

Figure 12. Del-1 deficiency is associated with inflammatory bone loss. (a) Sixteen-week-old C57BL/6 wild-type (WT) or Del-1 ${ }^{-1-}$ mice, of either gender, were assessed for periodontal bone levels. (b) Periodontal bone levels in female mice of the indicated ages. Negative values indicate bone loss relative to WT controls serving as the baseline. Data are means \pm SD (a $\& \mathbf{b}, n=4$; mice per group). ${ }^{\star} p<0.05 ;{ }^{* \star} p<0.01$ compared to corresponding control. 
Analysis of the periodontal inflammatory response by real-time quantitative PCR (qPCR) showed significant differences between 16-week-old Del-1-1- and age-matched wild-type mice, characterized by $>6$-fold elevated expression of IL-17A upon Del-1 deficiency (Figure 13); this difference was confirmed at the protein level by immunohistochemistry (Figure 14a). A less pronounced but statistically significant increase was observed in the transcript levels of other inflammatory mediators, such as proinflammatory and boneresorptive molecules (TNF, IL-6, RANKL), chemokines (CCL2, CCL20), chemokine receptors (CCR2, CCR6), receptors that amplify inflammation (C3aR, C5aR, TREM-1), and costimulatory molecules (CD40, CD86) (Figure 13). Importantly, the increased inflammation and bone loss in $\mathrm{Del}-1^{-1}$ mice was associated with increased infiltration of neutrophils in the gingiva (Figure 14b-c), consistent with lack of Del-1-mediated regulation of neutrophil trafficking. 


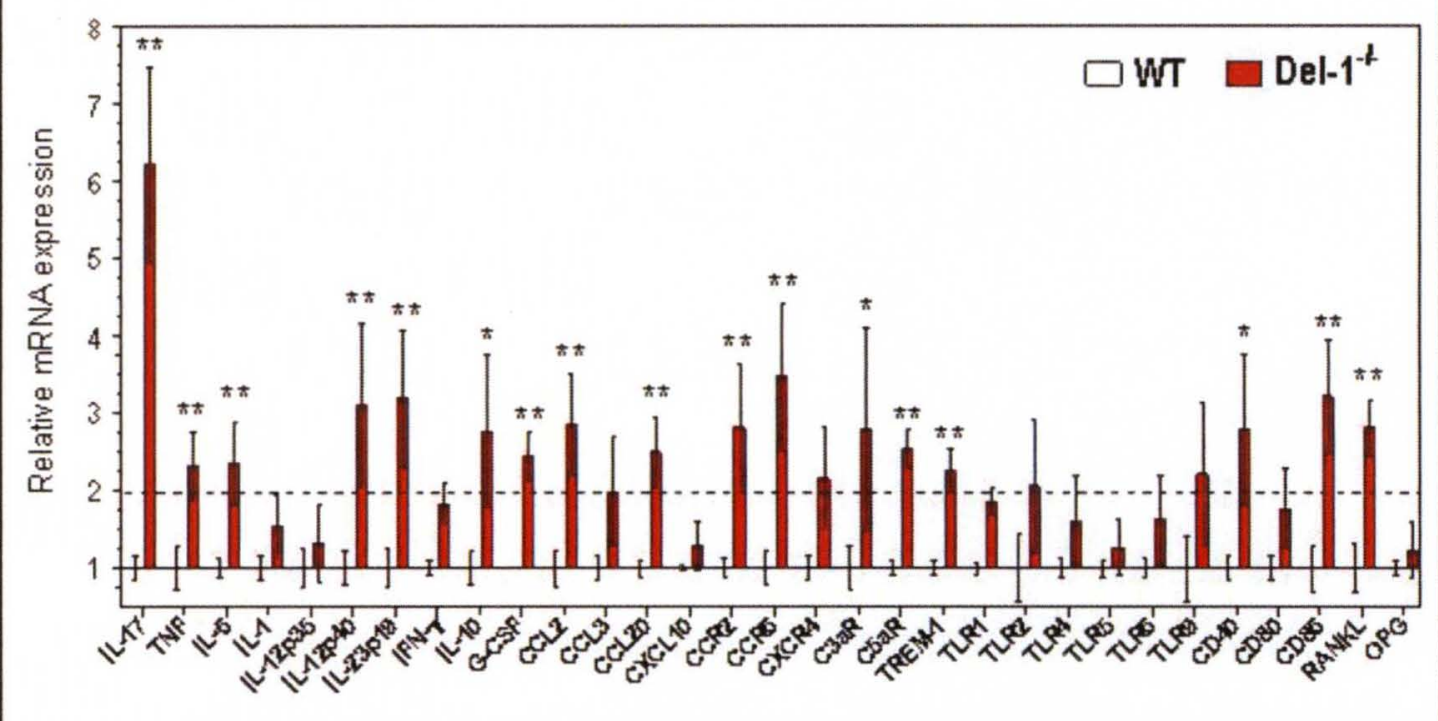

Figure 13. Del-1 deficiency is associated with inflammatory response in the periodontium. Sixteen-week-old C57BL/6 wild-type (WT) or Del-1-1- mice, of either gender, were assessed for inflammatory response. Gingiva were dissected from 16-week-old WT or Del-1-1- mice and gingival mRNA levels of the indicated molecules were determined by qPCR (normalized against GAPDH mRNA and expressed as fold change in Del-1-1- transcript levels relative to WT, the average value of which was taken as 1 . Data are means $\pm \operatorname{SD}(n=4$; mice per group). ${ }^{*} p<0.05 ;{ }^{* *} p<0.01$ compared to corresponding control. 


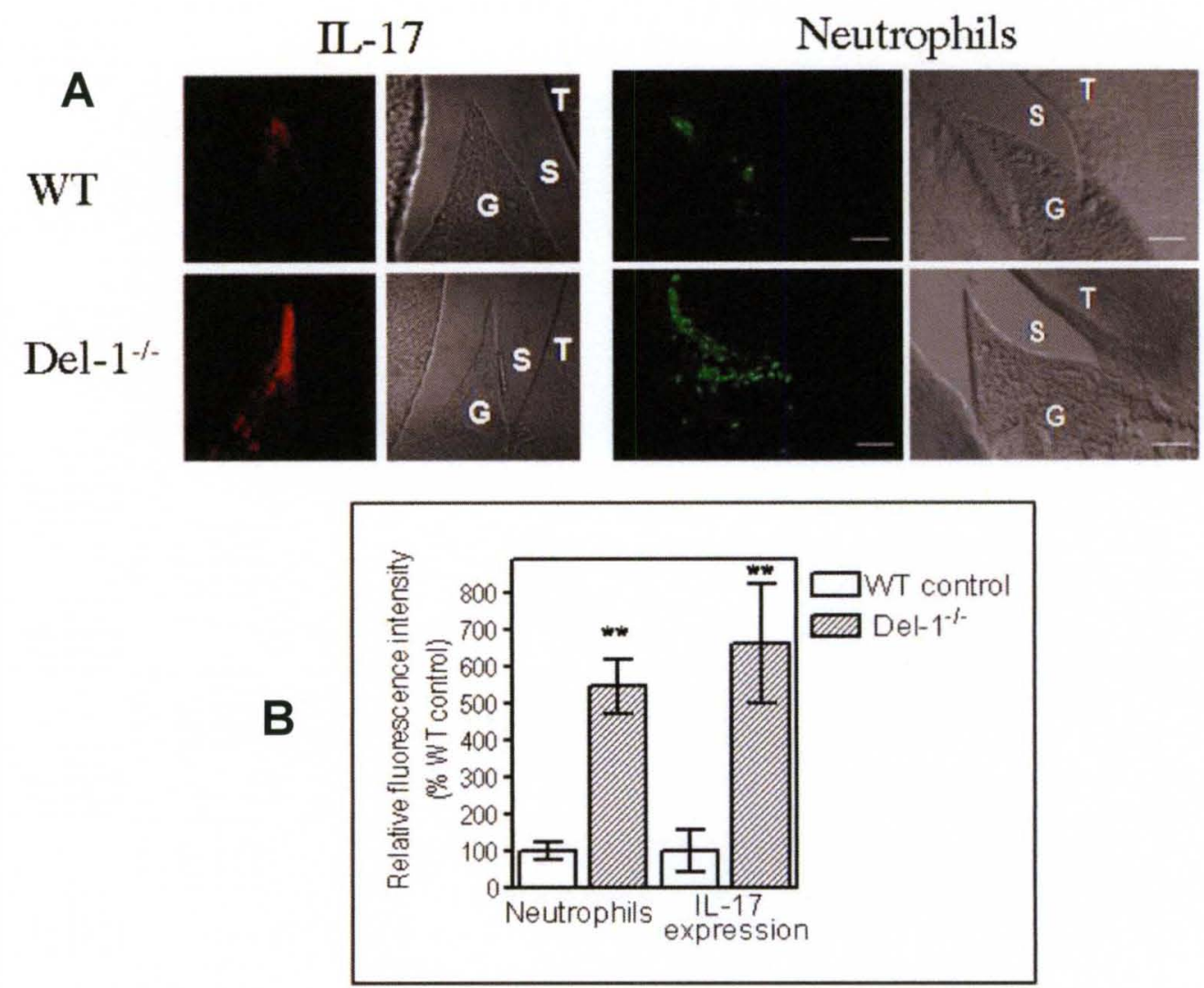

Figure 14. Increased recruitment of neutrophils and expression of IL-17 in the gingiva of $\mathrm{Del}-1^{-/-}$mice. (a) Sagittal sections of maxillary teeth from 16week-old WT or Del-1-1- mice were stained for IL-17A (upper left) or the neutrophil marker Ly6G (upper right). Shown are representative fluorescent confocal images (left) and corresponding differential interference contrast images (right). T, tooth; G, gingiva; S, sulcus. (b) The fluorescence intensities of images shown above (corresponding to IL-17 expression and neutrophil recruitment in the gingiva, respectively) and of additional representative images from independent 16-week-old wild-type (WT) and Del-1-1- mice were quantified using ImageJ analysis. Data are means \pm SD ( $n=5$ mice per group). ${ }^{* *} p<0.01$ compared to young control. 
Although it is the host inflammatory response that primarily can inflict damage upon the periodontal tissue, anaerobic oral bacteria are involved in the initiation and progression of periodontitis $[4,16,88]$. In this regard, Del- $1^{-1-}$ and wild-type mice initially harbored comparable levels of oral anaerobic bacteria; however, from the age of 8 weeks onward, Del-1 $1^{-1-}$ mice exhibited a significantly higher bacterial burden relative to age-matched wild-type controls (Figure 15a). The development of periodontal bone loss in $\mathrm{Del}-1^{-1-}$ mice was prevented by oral antibiotic treatment (Figure 15b), confirming the role of bacteria in this bone loss model, as in human periodontitis [88]. In summary, the periodontal tissue of Del$1^{-1-}$ mice displays unregulated neutrophil infiltration, elevated bacterial burden, and inflammatory bone loss, indicating that Del-1 deficiency compromises host homeostasis. 

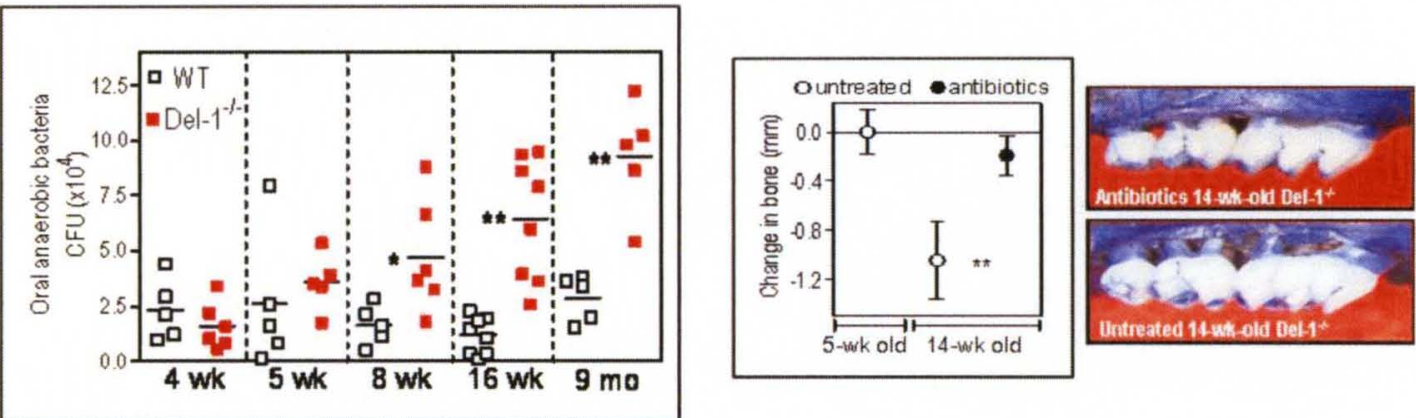

Figure 15. Del-1 deficiency is associated with elevated numbers of bacteria in the periodontium. (a) Wild type (WT) and Del- $1^{-1-}$ mice at the indicated ages were assessed for oral anaerobic bacteria (CFU shown for each mouse with horizontal lines denoting mean values). (b) Del-1/- mice were given antibiotics in the drinking water upon weaning (plain water served as control) and at 14 weeks were assessed for bone loss relative to 5 -week-old Del-1/- mice. Data are means $\pm S D$ (a \& b, $n=5$ mice per group). ${ }^{*} p<0.05 ;{ }^{* *} p<0.01$ compared to corresponding control. 
Inflammatory bone loss in Del-1 deficiency requires LFA-1 function and IL17R signaling

Since Del-1 acts as an antagonist of LFA-1 integrin-dependent neutrophil adhesion [52], we next addressed whether the bone loss seen in Del-1 ${ }^{-1-}$ mice could be attributed to increased LFA-1-mediated inflammatory cell recruitment. To this end, we examined the phenotype of mice with combined Del-1 and LFA-1 deficiency $\left(\mathrm{Del}-\mathrm{1}^{-1-}-\mathrm{LFA}-1^{-1}\right)$. We found that the periodontal bone loss associated with Del-1 deficiency was drastically (>75\%) reversed in Del-1 $1^{-1}-L F A-1^{-1-}$ mice (Figure 16a), which additionally displayed reduced neutrophil infiltration in the gingiva as compared to Del-1/- mice (Figure $16 \mathrm{~b}$ and Figure 17b). Therefore, the protective role of Del-1 against periodontitis may be mediated through regulation of LFA-1-dependent neutrophil trafficking. 
A

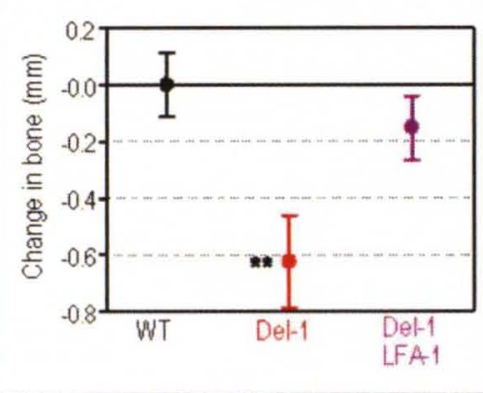

B

\section{Neutrophils}

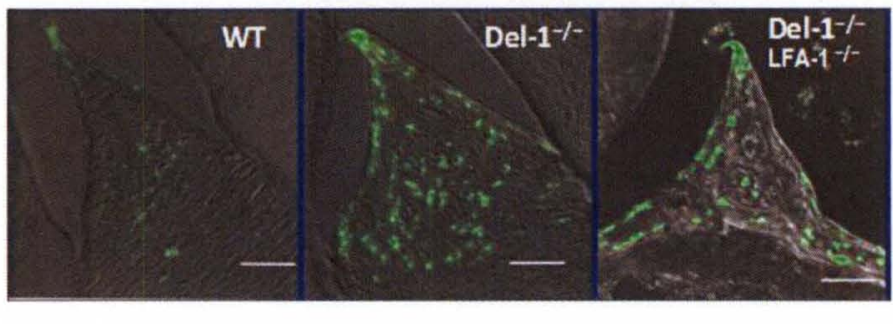

Figure 16. Increased bone loss and neutrophil number in Del-1 ${ }^{-1 /}$ is reversed in mice with dual Del-1/LFA-1 deficiency. (a) Twenty-week-old C57BL/6 wildtype (WT) mice or mice genetically deficient in the indicated molecules were assessed for periodontal bone levels. (b) Sagittal sections of interdental gingiva from the same mice were stained for the neutrophil marker Ly6G; shown are representative overlays of differential interference contrast and fluorescent confocal images. Data are means $\pm \operatorname{SD}$ (a \& b,$n=5$; mice per group). ${ }^{* *} p<0.01$ compared to WT control. Scale bars represent $50 \mu \mathrm{m}$. 
A
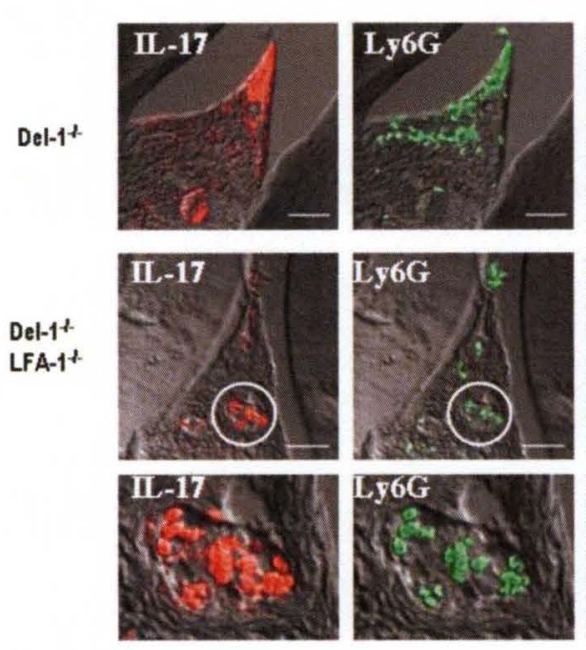

Del-1. LFA-1+
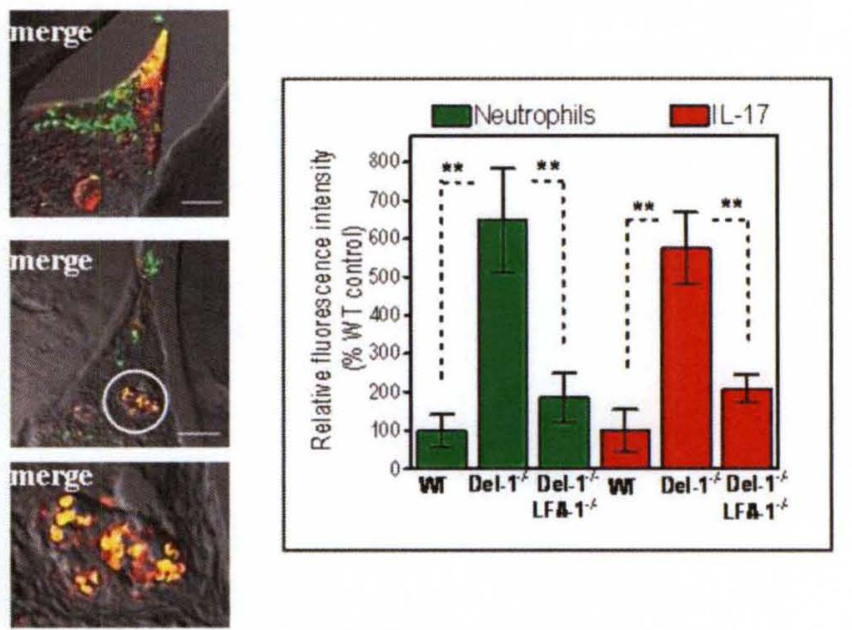

Figure 17. Del-1 deficiency-associated inflammatory response is reversed in mice with dual Del-1/LFA-1 deficiency. (a) Twenty-week-old Del-1 ${ }^{-1-}$ or Del$1^{-/-} / \mathrm{LFA}-1^{-/-}$mice were sacrificed to detect the indicated molecules including IL17 and Ly6G. Sections of interdental gingiva from the indicated mice were stained for IL-17 (left) and Ly6G (middle) with colocalization shown in merged images (right); the bottom row includes magnified views of the demarcated areas just above. (b) The fluorescence intensities of the images shown here and of additional representative images from independent mice were quantified using Image J analysis. Data are means $\pm \mathrm{SD}$ ( $\mathbf{a}$ and $\mathbf{b}, n=5$; mice per group). ${ }^{* *} p<$ 0.01 compared to indicated control. Scale bars represent $50 \mu \mathrm{m}$. 


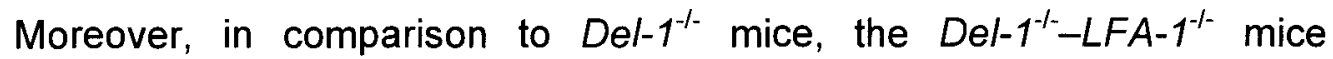
displayed decreased gingival levels of IL-17 (Figure 17a and b) due to, at least in part, reduced infiltration of neutrophils which expressed IL-17. In this regard, we observed colocalization of IL-17 and Ly6G (specific neutrophil marker) in gingival tissues of both $\mathrm{Del}-1^{-1-}$ and $\mathrm{Del}-1^{-1-}-L F A-1^{-1-}$ mice by immunohistochemistry (Figure 17a). This observation is consistent with the notion that much of the IL-17 released at sites of inflammation derives from innate immune cells, including neutrophils [89].

As $D e / 1^{-1-}$ mice had high IL-17 levels relative to both WT and Del-1 ${ }^{-1-}-L F A-$ $1^{-1 /}$ mice, we then sought to address the precise role of IL-17 in the observed bone loss due to Del-1-deficiency. Predicting the role of IL-17 in diseasewhether protective or destructive- is often uncertain, since IL-17 can mediate both antimicrobial host defenses and immunopathology [4, 22]. To conclusively address the role of IL-17, we generated mice with combined Del-1 and IL-17 receptor (IL-17R) deficiency. $D e l-1^{-1}-I L-17 R^{-/}$mice were completely protected against bone loss and were essentially indistinguishable from wild-type or $I L-17 R^{-}$ 1- mice (Figure 18a and Figure 19), suggesting that IL-17R signaling is required for induction of periodontal bone loss associated with Del-1 deficiency. The same experiment confirmed that $D e / 1^{-1-}-L F A-1^{-1-}$ mice are protected against periodontitis, whereas $L F A-1^{-/}$mice developed significant bone loss relative to wild-type mice (Figure 18a), suggesting that normal neutrophil trafficking (as opposed to excessive in the absence of Del-1 regulation) may mediate protection. All six genotypes used in these experiments had comparable bone 
levels in early age (5 weeks) (Figure 20), ruling out an innate etiology for the bone loss differences seen amongst the distinct mutant mice (Figure 18a). In addition, the increased load of oral anaerobic bacteria due to Del-1 deficiency (Figure 15a) was significantly reversed in both $D e l-1^{-1}-L F A-1^{-1}$ and $D e l-1^{-1-}-I L-$ $17 R^{-/-}$mice (Figure 18b). 
A

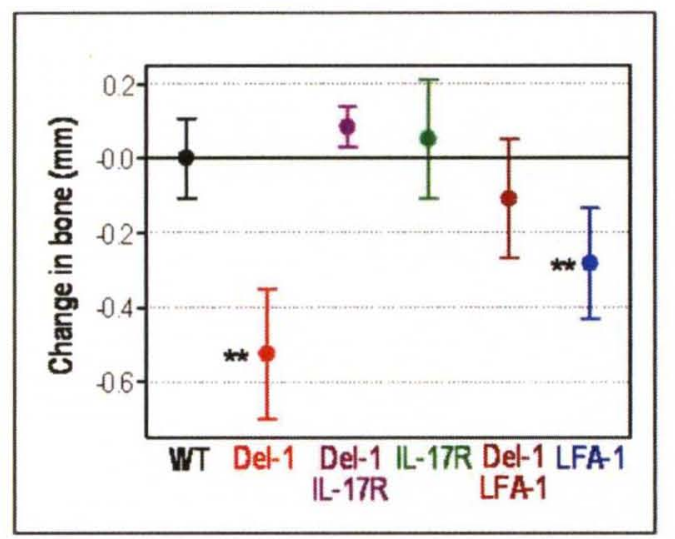

B

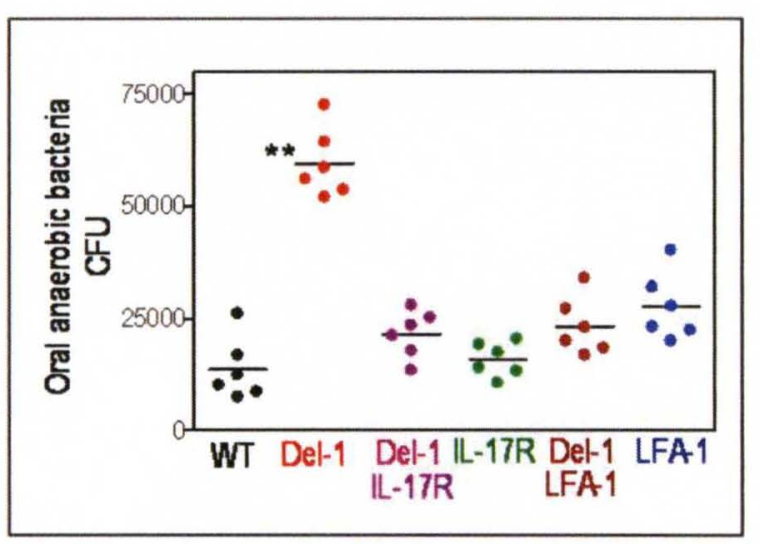

Figure 18. Del-1 deficiency-associated inflammatory bone loss is reversed in mice with dual Del-1/LFA-1 or Del-1/IL-17R deficiencies. (a) Twenty-weekold C57BL/6 wild-type (WT) mice or mice genetically deficient were assessed for periodontal bone levels. (b) CFU are shown for each mouse with horizontal lines denoting mean values. In a, negative values indicate bone loss relative to baseline bone levels of WT mice. Data are means \pm SD (a, $n=5 ; \mathbf{b}, n=9-11$ mice per group). ${ }^{* *} p<0.01$ compared to WT or indicated control. 
A

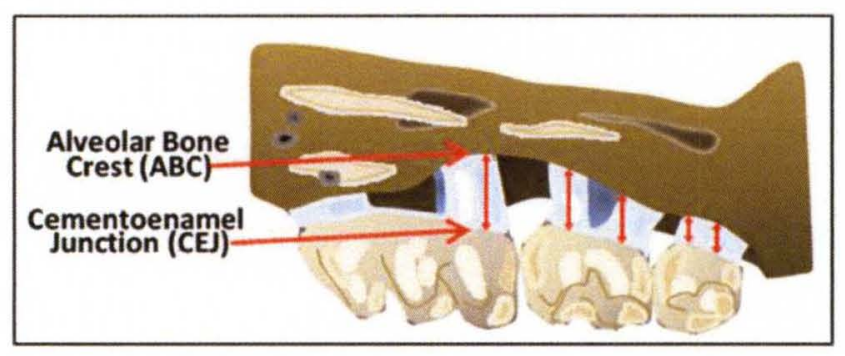

B

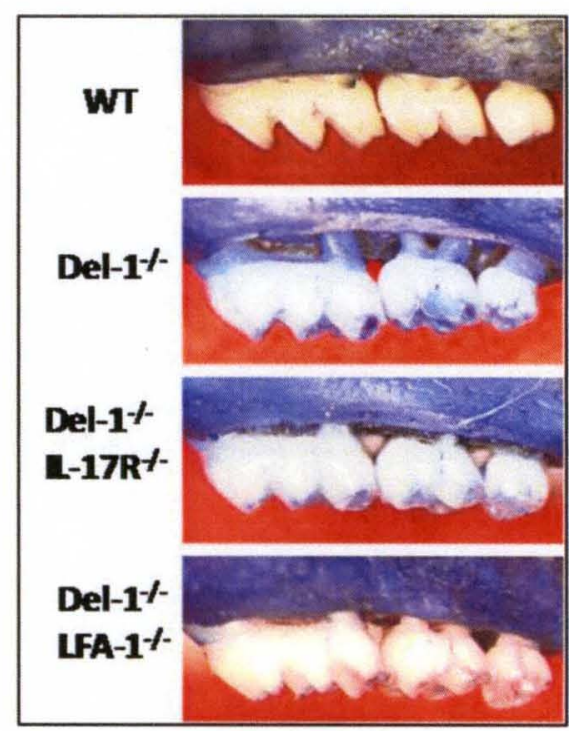

Figure 19. Del-1 deficiency-associated bone loss is reversed in mice with dual Del-1/LFA-1 or Del-1/IL-17R deficiencies. Representative images of maxillae (upper jaws) from the bone loss measurement experiment shown above. The bone gap [distance from the alveolar bone crest to the cementoenamel junction (a)] is greatest in the $\mathrm{Del}-1^{-/-}$mice, whereas mice with combined deficiencies (Del-1 $1^{-1-}-L F A-1^{-1-}$ or $\mathrm{Del}-1^{-1-}-I L-17 R^{-1-}$ ) have bone levels comparable to those of wild-type (WT) mice (b). See above for quantitative results. 


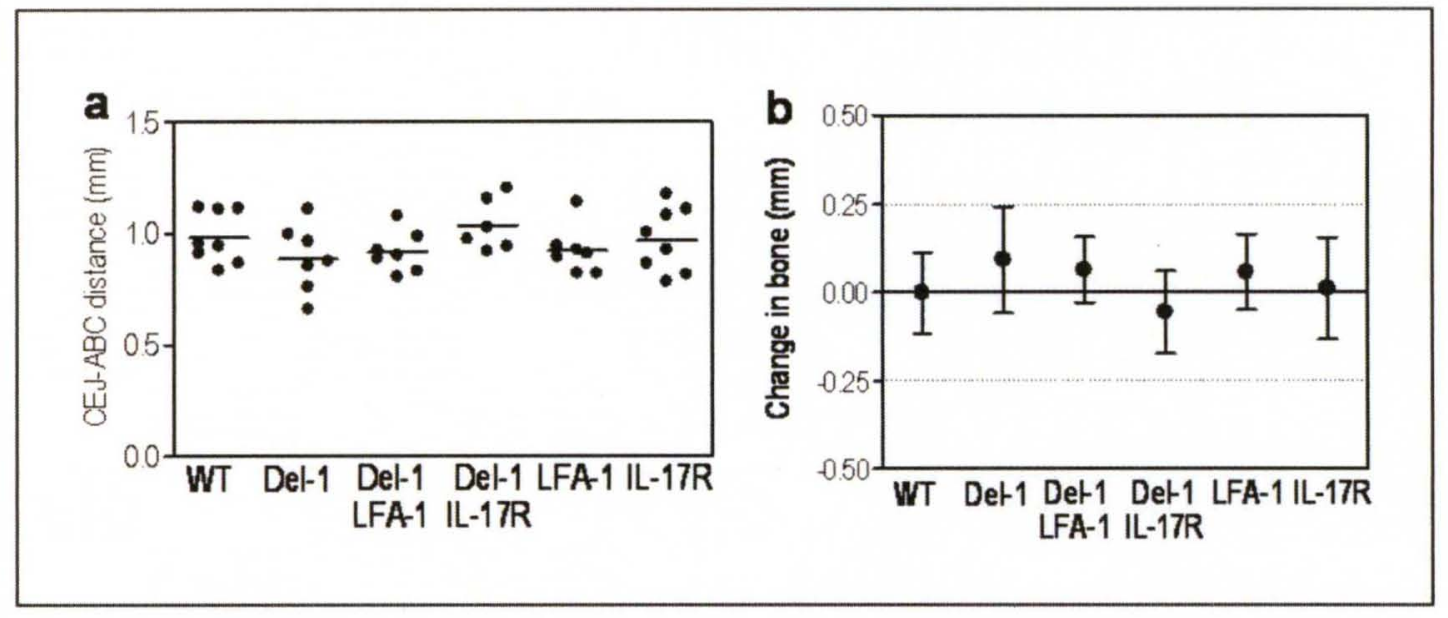

Figure 20. Bone loss in different genotype comparable periodontal bone levels in early-age mice regardless of genotype. Five-week-old C57BL/6 wildtype (WT) mice or mice genetically deficient in the indicated molecules were assessed for periodontal bone levels. The $\mathrm{mm}$ distance from the cementoenamel junction (CEJ) to the alveolar bone crest $(A B C)$ was measured at 14 predetermined sites in defleshed maxillae and was totaled for each mouse. (a) Data are shown for each mouse and horizontal lines indicate the mean value. (b) The data from panel 'a' were transformed to directly indicate bone level differences relative to the wild-type mice which served as the baseline. No significant differences were found among the groups ( $n=6$ to 8 mice per group). 
These findings indicate that Del-1 deficiency causes periodontal bone loss that is dependent on LFA-1-dependent neutrophil recruitment and IL-17R signaling. Moreover, conditions that restore tissue homeostasis in terms of periodontal bone maintenance (i.e., dual Del-1/LFA-1 or Del-1/LL-17R deficiencies) also reverse the numbers of oral bacteria to near normal levels.

\section{IL-17 regulates Del-1 expression as a function of age}

As IL-17 can orchestrate the production, chemotactic recruitment, and activation of neutrophils during inflammation $[26,27]$, we next examined whether IL-17 can additionally regulate Del-1 expression. To this end, we found that IL$17 R^{-1-}$ mice exhibited increased gingival Del-1 expression relative to wild-type controls (Figure 21, A-C). Consistent with the possibility that IL-17 downregulates

Del-1 expression, local microinjection $1 \mu \mathrm{g}$ of a neutralizing monoclonal antibody to IL-17 (clone M170) into the gingiva of old mice resulted in significant upregulation of Del-1 expression, whereas an isotype control had no effect (Figure 21D). Furthermore, the gingival expression of IL-17 was enhanced in old age (Figure 21E), in stark contrast to the decreased Del-1 expression in old mice (Figure 8B). Moreover, linear-regression analysis of Del-1 expression versus IL17 expression (data from figures $1 B$ and $4 D$, respectively, involving same set of 18-month-old mice) revealed a significant inverse association between IL-17 and Del-1 $(r 2=0.6274, p=0.0063 ;(F i g u r e 21 F)$. Taken together, the Figure 4 data demonstrate that Del-1 expression in the periodontal tissue is regulated by IL-17 as a function of age. 

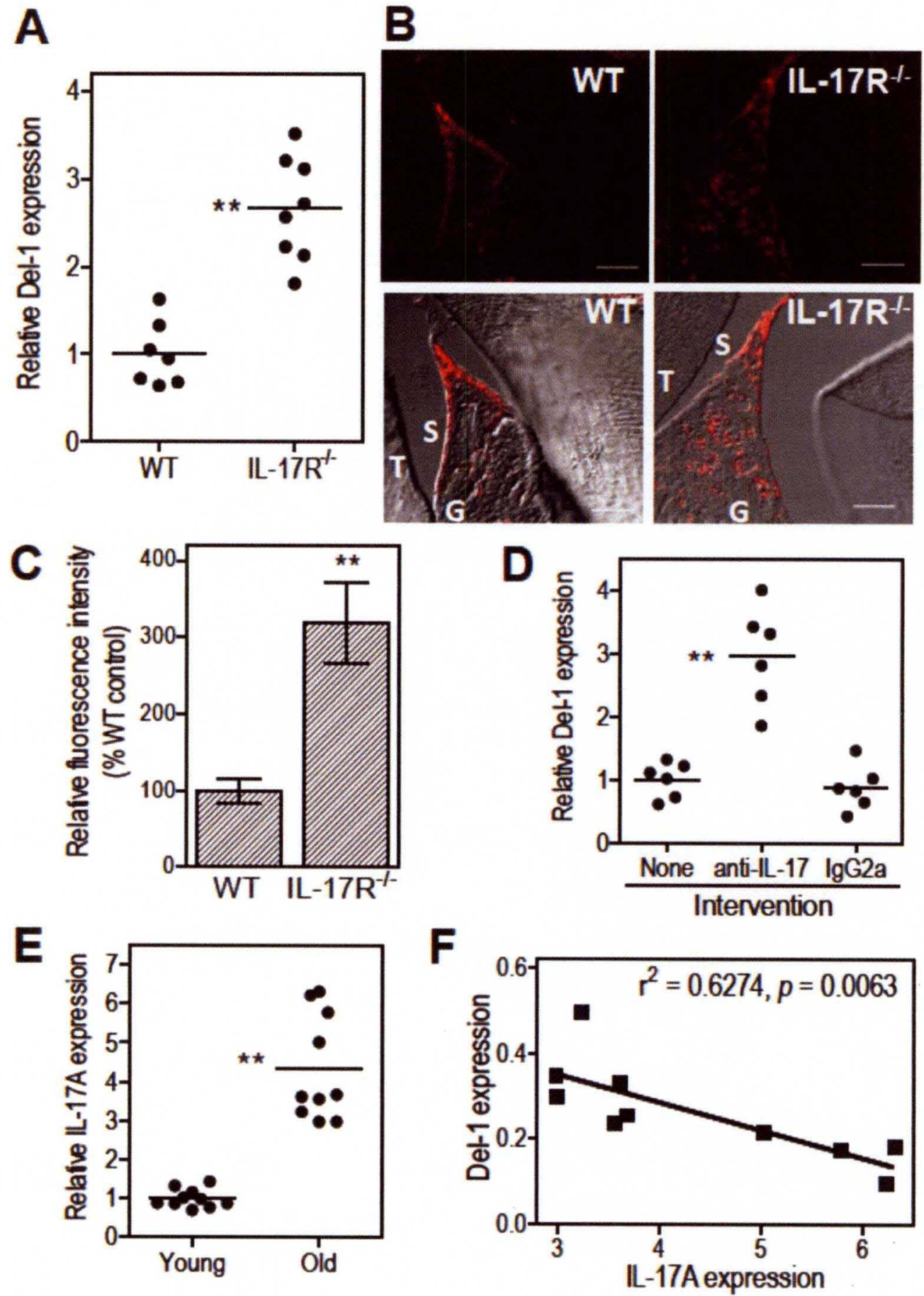
Figure 21. Del-1 expression is downregulated by IL-17 in old SPF mice. (a) Gingival Del-1 mRNA expression levels in wild-type (WT) and IL-17R-/- mice determined by qPCR (normalized against GAPDH mRNA and expressed as fold change relative to $W T$, the average value of which was taken as 1). Results are shown for each individual mouse. (b) Sagittal sections of interdental gingiva of WT and IL-17R-/- mice were stained for Del-1 protein; shown are representative fluorescent confocal images (upper row) and their overlays with corresponding differential interference contrast images overlays (lower row). Scale bar, $50 \mu \mathrm{m}$; $T$, tooth; $G$, gingiva; $S$, sulcus. (c) The fluorescence intensities of the images shown here in B and of additional representative images from independent mice were quantified using Image $J$ analysis (data are means $\pm S D$; $=5$ mice per group) (d) Anti-IL-17 mAb (M210) and IgG2a isotype control were microinjected into the palatal gingiva and qPCR was used to determine gingival Del-1 mRNA expression. (e) Gingival IL-17 mRNA expression was determined in young (8-10week old) and old (18 months of age) mice using GPCR. (f) Linear-regression analysis of the Del-1 expression versus IL-17 expression in old mice. ${ }^{* *} \mathrm{p}<0.01$ compared to untreated, WT, or young controls. 
Local administration of soluble Del-1 reverses periodontal inflammation in old mice.

We next determined whether recombinantly expressed soluble Del-1 could be exploited therapeutically to reverse periodontal inflammation in old mice, which express relatively low levels of Del-1 (Figure 8 and Figure 9). Indeed, local gingival microinjection of soluble Del-1 resulted in reduced neutrophil infiltration (Figure 22a) and diminished expression of IL-17 (Figure 22b) and TNFa (Figure 22c) in the periodontium compared to similar treatment with BSA control (Figure 22d). Notably, Del-1 treatment of old mice suppressed both constitutive (naturally occurring) inflammation (Figure 22a, b, c; upper rows) as well as inflammation induced by exogenous oral inoculation with the human pathogen Porphyromonas gingivalis (Figure 22a, b, c; lower rows). The ability of soluble Del-1 to reduce expression of IL-17 and TNFa protein was confirmed at the mRNA level by qPCR which additionally revealed reduced transcript levels of a number of other inflammatory mediators (such as proinflammatory cytokines, chemokines, chemokine receptors, pattern-recognition and complement receptors, and costimulatory molecules; (Table 2). These data provide proof-of-concept evidence that Del-1 has therapeutic potential for the treatment of periodontal inflammation, and perhaps other neutrophil-mediated inflammatory diseases [12, $42,85,86]$. 


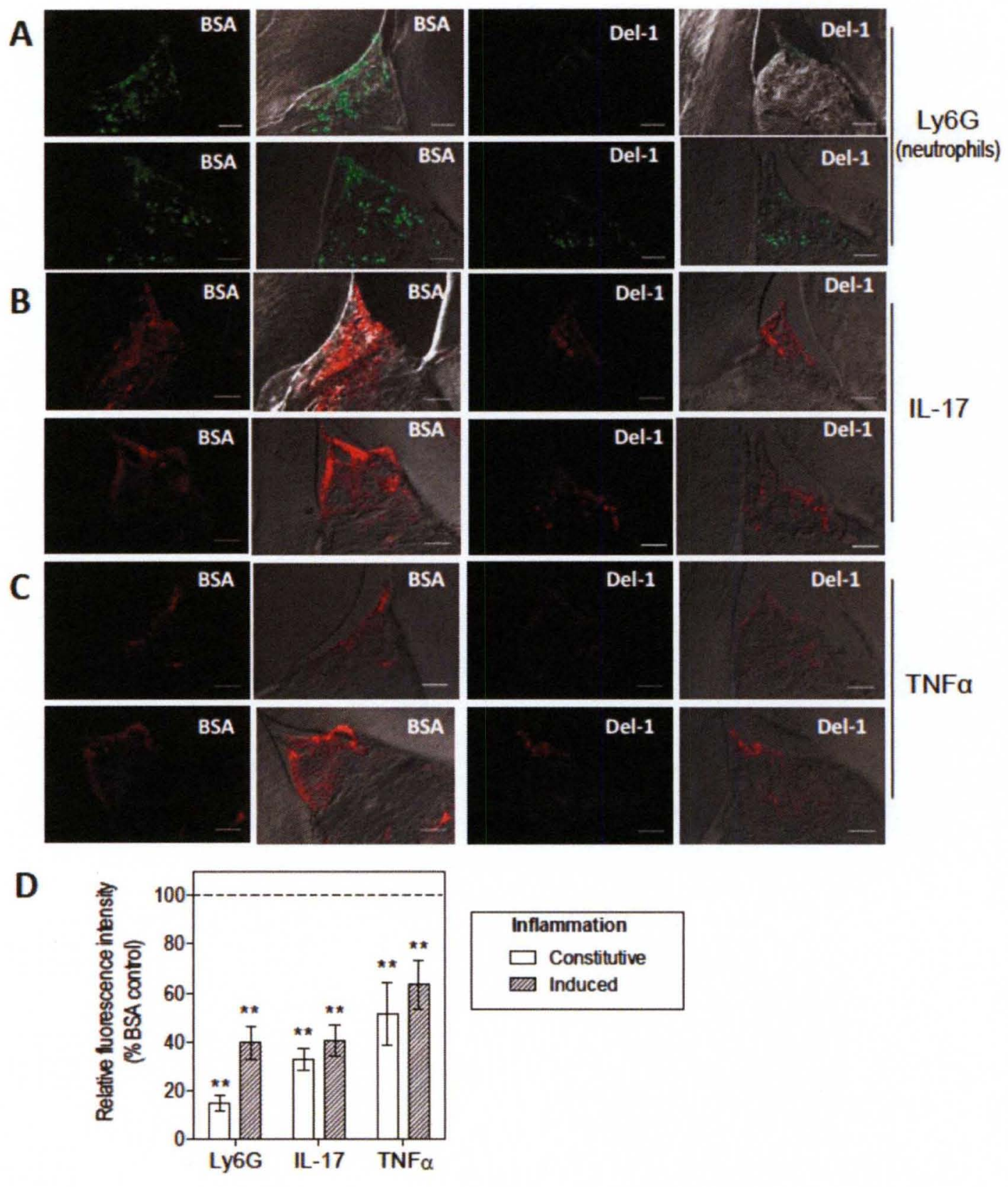

Figure 22. Del-1 treatment reverses periodontal inflammation in old mice.

Eighteen-month old C57BL/6 mice were microinjected in the gingiva with BSA (control) or Del-1, as indicated. In addition, the mice were orally administered $P$. gingivalis in $2 \%$ carboxy-methylcellulose vehicle (a, b, c; lower rows) or vehicle control (a, b, c; upper rows) and were sacrificed $12 \mathrm{~h}$ later. Sagittal sections of 
interdental gingiva were stained for the neutrophil marker Ly6G (a), IL-17A (b), or TNFa (c). Shown are typical fluorescent confocal images (left) and their overlays with corresponding differential interference contrast images (right). (d) The fluorescence intensities of the images shown here and of additional representative images from independent mice were quantified using ImageJ analysis; data were expressed as \% intensity of the Del-1-treated groups relative to the BSA-treated controls, the value of which was set to $100 \%$ ('Induced inflammation' refers to the groups inoculated with $P$. gingivalis). Data are means $\pm \mathrm{SD}$ ( $\mathrm{n}=5$ mice per group). ${ }^{* *} \mathrm{p}<0.01$ compared to BSA-treated controls. 


\begin{tabular}{l|cc} 
& \multicolumn{2}{c}{ Fold change vs. } \\
Molecule & Del-1-untreated controls \\
\cline { 2 - 3 } & CMC & Pg \\
\hline IL-17 & 0.19 & 0.25 \\
\hline TNF & 0.50 & 0.51 \\
\hline IL-6 & 0.25 & 0.24 \\
\hline IL-1 & 0.50 & 0.25 \\
\hline RANKL & 0.49 & 0.25 \\
\hline G-CSF & 0.12 & 0.25 \\
\hline CCL2 & 0.48 & 0.49 \\
\hline CCL3 & 1.02 & 0.51 \\
\hline CCL20 & 0.24 & 0.49 \\
\hline CXCL10 & 0.25 & 0.26 \\
\hline CCR2 & 0.26 & 0.12 \\
\hline CCR6 & 0.25 & 0.13 \\
\hline CXCR4 & 0.50 & 0.24 \\
\hline C3aR & 0.49 & 0.49 \\
\hline C5aR & 0.50 & 0.25 \\
\hline TREM-1 & 0.49 & 0.24 \\
\hline TLR1 & 0.24 & 0.24 \\
\hline TLR2 & 0.26 & 0.25 \\
\hline TLR4 & 0.25 & 0.12 \\
\hline TLR5 & 0.51 & 0.51 \\
\hline TLR6 & 0.27 & 0.26 \\
\hline TLR9 & 0.25 & 0.51 \\
\hline CD40 & 0.24 & 0.25 \\
\hline CD80 & 0.25 & 0.25 \\
\hline CD86 & 0.50 & 0.49 \\
\hline
\end{tabular}


Table 2. Reduced mRNA levels of inflammatory mediators in the gingiva of aged mice after local administration of soluble Del-1. Eighteen-month-old C57BL/6 mice were microinjected with BSA (control) or Del-1 in the palatal gingiva between the first and the second molar teeth. The mice were then orally inoculated with $10^{9} \mathrm{CFU}$ Porphyromonas gingivalis in $2 \%$ carboxymethylcellulose $(\mathrm{CMC})$ or $\mathrm{CMC}$ only, and were sacrificed $12 \mathrm{~h}$ later. The interdental gingiva (i.e., between first and second molar teeth) were dissected and processed for quantitative real-time PCR ( $q P C R$ ) to determine gingival mRNA levels of the indicated molecules (normalized against GAPDH mRNA levels and expressed as fold change of Del-1-treated relative to corresponding BSA-treated controls). To ensure enough tissue material, dissected interdental gingiva from 5 mice per group were pooled before use in the qPCR. Consistent results were obtained from an identical independent experiment. 


\section{Del-1 expression is reduced in periodontitis patients.}

According to BLAST analysis, human and mouse Del-1 share $96 \%$ aminoacid sequence identity, which readily explains why human Del-1 is functional in mice [90]. The purpose of these studies was to determine if the low Del-1 and high IL-17 expression seen in mouse periodontitis was relevant in human periodontitis. Tissues, which were harvested from healthy and diseased areas in the same subject, were stained for Del-1 expression. According to our preliminary data, Del-1 expression was dramatically reduced in diseased area as compared to healthy areas (Figure 22A). We next determined if IL-17 expression increased in diseased gingiva. We found, in contrast to reduced Del-1 expression, that IL-17 expression was markedly increased in diseased areas (Figure 22B). Those results were consistent what we have found in old or Del-1 deficient mice (see above). 


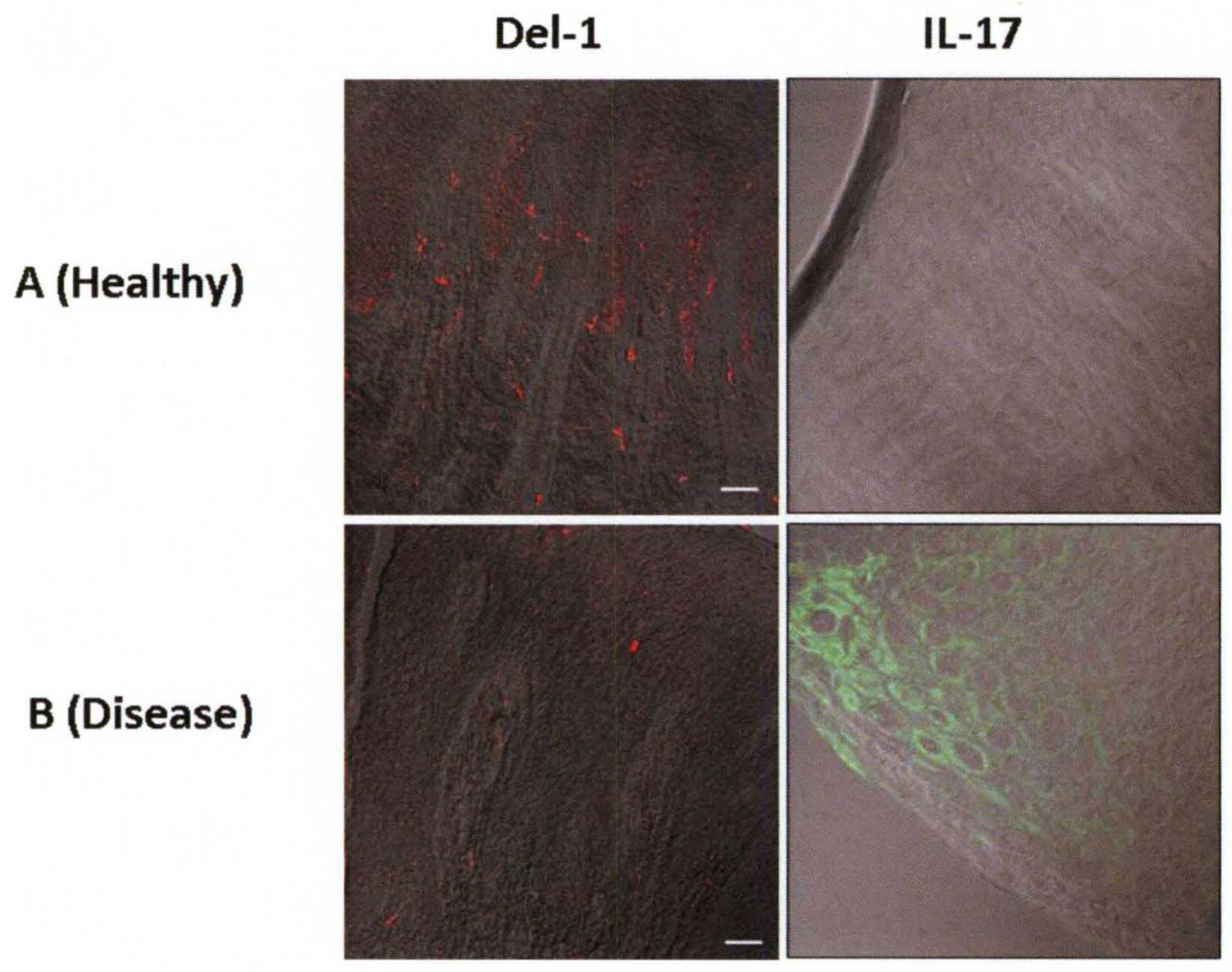

Figure 23. Expression of IL-17 and Del-1 in human gingival. (a) Sagittal sections of human gingiva from healthy (a) or diseased (b) sites were stained for Del-1 (left) or IL-17A (right). This is a preliminary data and utilized from two patients. 


\section{DISCUSSION}

We showed here for the first time that Del-1 (a) serves a mechanism by which a tissue can control the local inflammatory response to prevent immunopathology and (b) may be a promising novel therapeutic for inflammatory diseases. Specifically, Del-1 is required for homeostatic inhibition of inflammatory periodontal bone loss involving LFA-1-dependent neutrophil recruitment and IL$17 R$ signaling.

Importantly, Del-1 ${ }^{-1-}$ mice developed periodontitis naturally in a chronic setting of dysregulated neutrophil recruitment without requiring experimental intervention (e.g., superinfection with a human periodontal pathogen or injection of bone loss-inducing agents such as lipopolysaccharide) as is often required in animal periodontitis models [91]. A phenotype comparable to that of $\mathrm{Del}-1^{-1 /}$ mice was mirrored in wild type old mice, in which inflammatory bone loss increased linearly with reduced expression of Del-1.

In turn, IL-17, which was expressed at higher levels in old age, negatively regulated Del-1 expression. This finding reveals a novel mechanism whereby IL17 orchestrates neutrophil recruitment. Previously, it was shown that IL-17 promotes granulopoiesis and induces the chemotactic recruitment, activation, and survival of neutrophils [26-28]. Now we show that IL-17 also suppresses endogenous inhibitory mechanisms to facilitate the recruitment of neutrophils to 
sites of infection. This function may be beneficial in the acute defense against infection, although- as shown here- it can become detrimental under chronic conditions. Persistent recruitment and infiltration of neutrophils into peripheral tissues may contribute to the pathogenesis of additional chronic inflammatory diseases, such as rheumatoid arthritis, inflammatory bowel disease, and chronic inflammatory lung diseases $[12,13,42,92]$. Therefore, interventional approaches aiming to downregulate the recruitment or activation of neutrophils (e.g., Del-1 or anti-IL-17 biologics) may offer treatment solutions.

The spontaneous disease phenotype of Del-1/- mice suggests that the tissue may have greater control over the local host inflammatory response than the immune system itself. Del-1 acts locally in tissues that express it, such as the periodontium, by competing with LFA-1- dependent adhesion of neutrophils to endothelial ICAM-1 [52]. The restricted expression pattern of Del-1 likely confers its tissue-specific anti-inflammatory activity [43]. This role of Del-1 is in line with recent findings that growth differentiation factor-15, locally produced in the heart, protects the infarcted myocardium from excessive neutrophil infiltration by inhibiting integrin activation [14]. This recent study and our current findings support an emerging concept that tissues have evolved distinct local homeostatic mechanisms to control inflammatory cell recruitment and prevent tissue damage.

To our knowledge, the abrogation of periodontitis in $\mathrm{Del}-1^{1-}-I L-17 R^{-1-}$ mice represents the first time that IL-17R signaling is causally linked to periodontal bone loss, consistent with the elevated level of IL-17 in human periodontitis [4, 93, 94]. Our findings are thus consistent with the elevated levels of IL-17 in 
human periodontitis $[4,93-95]$ and in mouse periodontitis models $[74,96]$. IL-17 was also shown to stimulate antimicrobial immunity and thereby to inhibit pathogen-initiated bone loss in a relatively acute periodontitis model [97]; however, chronic IL-17R signaling can turn an acute inflammatory response into chronic immunopathology, as seen in rheumatoid arthritis [4, 22]. In this context, IL-17 can mediate connective tissue destruction and bone resorption efficiently and independently of IL-1 $\beta$ and TNF- $\alpha$; the underlying mechanisms are largely dependent on induction of matrix metalloproteases and RANKL (receptor activator of nuclear factor-kB ligand) $[22,98]$. In this regard, the Del-1/- mice exhibited 3-fold higher RANKL expression in the gingiva than wild-type controls, although both groups had similar expression of the RANKL inhibitor, osteoprotegerin (OPG) (Fig. 13).

Furthermore, the recent demonstration that neutrophils express RANKL underscores their potential to directly engage in inflammatory bone destruction [99]. Although IL-17 is a signature cytokine of the CD4+ T-helper 17 subset, much of the IL-17 in inflammatory sites is actually contributed by innate immune sources [89]. Accordingly, we observed colocalization of IL-17 and neutrophils in the gingiva. Neutrophils are thought to mediate periodontal tissue destruction through the release of inflammatory cytokines, oxygen radicals, and matrixdegrading metalloproteases $[19,100]$. The interplay between neutrophils and IL17 may generate a positive feedback loop of persistent neutrophil-mediated inflammation, which can be reversed, however, by local administration of Del-1, as indicated by its ability to inhibit IL-17 expression. This finding and our data that 
the age-associated downregulation of Del-1 was mediated by $\mathrm{IL}-17$ suggest a reciprocal cross-regulation of the two molecules.

Dysregulated LFA-1-dependent recruitment is apparently the proximal cause for the increased neutrophil infiltration in the gingiva of Del-1-deficient mice. However, IL-17, the gingival expression of which was significantly elevated in genetic and age-associated Del-1 deficiency, could contribute to sustaining high neutrophil numbers. In this regard, IL-17 promotes granulopoiesis and orchestrates the recruitment, activation, and survival of neutrophils $[26,27]$. Moreover, IL-23, which is a potent inducer of $\mathrm{IL}-17$ production by both adaptive and innate immune sources $[101,102]$, was also upregulated (both IL-12/IL$23 p 40$ and IL-23p19 subunits were expressed at $\approx 3$-fold higher levels in $\mathrm{Del}-\mathrm{1}^{-1-}$ relative to wild-type mouse gingiva; Fig. 14a). Therefore, Del-1 deficiency causes enhanced neutrophil recruitment and IL-17 production, the interplay of which could generate a positive feedback loop of persistent neutrophil-mediated inflammation.

Neutrophils are key effectors of periodontal tissue destruction through the release of inflammatory cytokines, oxygen radicals, and matrix-degrading metalloproteases $[16,87,100]$. The recent demonstration that neutrophils express RANKL underscores their potential to directly engage in inflammatory bone destruction $[103,104]$. Although neutrophils play crucial roles in the acute defense against infection, their persistent recruitment and infiltration into tissues may contribute to the pathogenesis of additional chronic inflammatory diseases, such as rheumatoid arthritis, inflammatory bowel disease, and chronic 
inflammatory lung diseases $[12,13,42,85,86]$. Therefore, interventional approaches aiming to downregulate the recruitment or activation of neutrophils (e.g., Del-1 or anti-IL-17 biologics) may offer treatment solutions.

Since the proximal consequence of Del-1 deficiency is elevated LFA-1dependent neutrophil recruitment, the reason(s) for the increased oral microbial burden in Del- $1^{-1-}$ mice is not obvious. It is possible that excessive cellular recruitment and inflammation creates an environment that impairs the neutrophil defensive functions, as seen in sepsis [105], leading to uncontrolled bacterial growth. Indeed, in sepsis, neutrophils can undergo 'immune paralysis', a condition largely dependent on C5aR signaling [105]. Interestingly, the expression of $\mathrm{C} 5 \mathrm{aR}$ (and other receptors that amplify inflammation such as $\mathrm{C} 3 \mathrm{aR}$ and TREM-1) was elevated in the absence of Del-1 (Fig. 13). Alternatively (or additionally), under inflammatory conditions, the gingival inflammatory exudate becomes a rich source of nutrients, such as hemin-derived iron and degraded host proteins, which would favor the growth of periodontal bacteria $[88,106]$. The notion that inflammation contributes to bacterial growth is consistent with our observation that the high oral microbial burden associated with Del-1 deficiency was restored to near normal levels in $D e l-1^{-1-}-L F A-1^{-1-}$ and $D e /-1^{-1-}-I L-17 R^{-1-}$ mice, which had reduced periodontal inflammation relative to $\mathrm{Del}-1^{-1-}$ mice. This positive reinforcement loop between inflammation and bacterial growth can perpetuate inflammatory tissue destruction, since increased levels of bacteria can in turn elicit even higher inflammation and bone loss. 
The majority of the adult population experiences some form of periodontal disease and an estimated $10-15 \%$ develops severe periodontitis, which has significant economic consequences [107] and is a risk factor for systemic conditions [37, 76, 108, 109]. Moreover, old age is associated with increased prevalence and severity of periodontitis and a number of other chronic inflammatory diseases $[2,82,84,110]$. The term 'inflamm-aging' was aptly coined to describe the heightened chronic inflammatory state often associated with old age in humans [111]. In this regard, the elderly show inappropriately high periodontal inflammatory responses relative to young individuals following comparable de novo biofilm formation [84]. A similar condition may apply to old mice which develop overt periodontitis [74]. From a mechanistic viewpoint, little is known regarding the impact of aging on innate immunity and inflammatory diseases [82, 84]. However, the reduced expression of Del-1 could be a major mechanism linking advanced age to destructive periodontal inflammation.

Our findings support the feasibility of controlling the influx of neutrophils and ensuing inflammation through Del-1 treatment. Conventional periodontal treatment is often not sufficient by itself to control destructive inflammation and many patients develop recurrent disease [112]. Del-1 may thus offer a promising approach to treat periodontitis and reduce the risk for associated systemic diseases, whereas the anti-inflammatory properties of Del-1 may also find application in other inflammatory and autoimmune diseases $[12,42,85,86]$. 


\section{CONCLUSION}

We showed that Del-1, a novel inhibitor of integrin-dependent neutrophil adhesion, regulates local tissue-specific inflammation and controls chronic inflammatory disease. Upon aging, normal mice developed periodontitis accompanied by diminished Del-1 expression. Consistent with a homeostatic role for Del-1, Del-1/- mice developed spontaneous periodontitis featuring excessive local neutrophil infiltration and IL-17 expression. Disease was reversed in Del-1 ${ }^{-1}$ mice with additional deficiencies in the LFA-1 integrin or the IL-17 receptor. Intriguingly, Del-1 and IL-17 were reciprocally cross-regulated and the diminished expression of Del-1 in old age was associated with elevated IL-17 expression.

The function of the immune system declines with age. It therefore follows that the complex cytokine network that orchestrates cell-cell interactions is also affected by age. Those age-associated changes in cytokine production have been investigated previously in both humans and rodents [113, 114]. For example, it has been shown that aging increased inflammation by inducing production of proinflammatory cytokines and chemokines such as IL-6 and CCL2, respectively [115]. It is well known that overproduction of IL-6 is associated with a spectrum of age-related conditions including cardiovascular disease, osteoporosis, arthritis, type 2 diabetes, certain cancers, and periodontal disease. Consistently, we have shown that the age-association of certain pro- 
inflammatory cytokines, including IL-1 $\beta$, TNF- $\alpha$, IL-17A and IL-6, increased in the gingivae [74]. We also, in this study, found that reduction of inflammatory cytokines and chemokines production increased in Del-1 deficient mice. Together, it is clear that the host immune system is dysregulated by age.

Homeostasis following periodontal injury is essential for the tissue regeneration or repair. Dysregulated homeostatis is associated with chronic inflammatory diseases, including rheumatoid arthritis, psoriasis, inflammatory bowel disease and periodontitis afflicting millions of people worldwide. Susceptibility to chronic disease is most likely genetically determined and immune response play a crucial role for the disease prognosis. Pro- or antiinflammatory cytokines induced locally modulate the course of the response whereby they can modulate the host response, which is the resistance or susceptibility to the particular pathogen. For example, it has been shown that IL4, IL-10, IL-13 and TGF- $\beta$ are some of key anti-inflammatory cytokines resulting tissue homeostasis in periodontium [17]. IL-4 contributes to negative immune regulation by reducing IL-2 receptor [116] or production of TNF- $\alpha$, IL-1 and IL-6 in monocytes [117]. IL-10 has been show to reduce Th1 cell proliferation and cytokine production such as IFN- $\gamma$ [118]. IL-13 is other potent immune modulator and might contribute to the development of Th2 immune response by reducing IL-12 production [119]. Importantly, production of those anti-inflammatory cytokines, including IL-4, IL-10 and TGF- $\beta$, is reduced by age $[114,120]$.

All together, we think that increased inflammation by age due to dysregulated host immune responses to microorganisms could negatively affect 
Del-1 expression. Indeed, we observed that inflammation resulted in reduced expression of Del-1 in our ligature-induced periodontitis model and it also is reported that Del-1 expression was regulated inflamed tissue and the endothelial cell upon stimulated by TNF- $\alpha$ [52].

Another possible mechanism that could explain why we see more inflammatory response in old mice might be changes in neutrophils' function seen in the elderly [121]. Neutrophils are an important part of the immune response towards invading organisms. They are the first line of defense, forming part of the innate immune response. With aging, decreases have been recently demonstrated in specific cell functions, such as apoptosis/survival of PMN [121]. These alterations might contribute to the increased incidence of infections with aging. Apoptosis plays an important role in the regulation of tissue development, differentiation and homeostasis as well as in several pathologies in chronic inflammatory diseases $[122,123]$. Mature neutrophils undergo spontaneous apoptosis very rapidly when maintained in vitro; this sensitivity to apoptosis regulates both their production and their survival. However, their lifespan has been reported to be reduced by age [124], leading to the increased number of apoptotic cells in the inflamed area. To sustain homeostasis, these apoptotic neutrophils are quickly removed by professional phagocytes such as macrophages [125]. The engulfment of apoptotic cells provides a benefit to the host by preventing the inflammation and tissue damage that can be caused by intracellular materials being released from dying cells. Thus, it is expected to have more inflammation upon the burden of apoptotic cells exceeds the capacity 
of the macrophages. Importantly, Del-1 has been reported to bind specifically apoptotic cells by recognizing phosphatidylserine [72]. In this study, it was clearly shown that Del-1 can work as a bridge between apoptotic cells and phagocytes [72]. Since macrophages are a key player to clean up apoptotic cells, it can be questioned the number macrophage in the elderly or Del-1 deficient mice. It has been reported that macrophage function, rather than their number, is affected by age [126]. We also found showed that CD14 expression showed a similar expression level in Del-1 deficient or wild type mice (data not shown). Together, reduced engulfment of apoptotic neutrophils by macrophages could lead to increased inflammation seen in the elderly.

We demonstrated that Del-1 is required for homeostatic inhibition of inflammatory periodontal bone loss involving LFA-1-dependent neutrophil recruitment and IL-17R signaling. In Del- $1^{-/}$mice, periodontitis developed spontaneously in a chronic setting of dysregulated neutrophil recruitment without requiring experimental intervention (e.g., superinfection with a human periodontal pathogen or injection of bone loss-inducing agents such as lipopolysaccharide) as often required in animal periodontitis models [91]. A phenotype comparable to that of Del- $1^{-1}$ mice was mirrored in normal old mice, in which inflammatory bone loss increased linearly with reduced expression of Del-1.

We found that the periodontal bone loss associated with Del- 1 deficiency was drastically $(>75 \%)$ reversed in Del- $1^{-1-}-L F A-1^{-1-}$ mice, which additionally displayed reduced neutrophil infiltration in the gingiva as compared to $\mathrm{Del}-\mathrm{f}^{-1-}$ 
mice. Therefore, the protective role of Del-1 against periodontitis is mediated through regulation of LFA-1-dependent neutrophil trafficking.

Moreover, in comparison to Del-1 $1^{-1-}$ mice, the $D e l-1^{-1-}-L F A-1^{-1-}$ mice displayed decreased gingival levels of IL-17 due to, at least in part, reduced infiltration of neutrophils, which expressed IL-17. In this regard, we observed colocalization of IL-17 and Ly6G in gingival tissues of both $\mathrm{Del}-1^{-/-}$and $\mathrm{Del}-1^{-/}-$ $L F A-1^{-1-}$ mice by immunohistochemistry. This observation is consistent with the notion that much of the IL-17 released at sites of inflammation derives from innate immune cells, including neutrophils [89].

The development of periodontitis was abrogated in Del- $1^{-1-}-I_{L}-17 R^{-1 /}$ mice and this, to our knowledge, is the first time that IL-17R signaling is causally linked to alveolar bone loss. Our findings are thus consistent with the elevated levels of IL-17 in human periodontitis [4, 93-95] and in mouse periodontitis models [74, 96]. IL-17 was also shown to stimulate antimicrobial immunity and thereby to inhibit pathogen-initiated bone loss in a relatively acute periodontitis model [97]; however, chronic IL-17R signaling can turn an acute inflammatory response into chronic immunopathology, as seen in rheumatoid arthritis [4, 22]. In this context, IL-17 can mediate connective tissue destruction and bone resorption efficiently and independently of IL-1 $\beta$ and TNF- $\alpha$; the underlying mechanisms are largely dependent on induction of matrix metalloproteases and RANKL (receptor activator of nuclear factor-kB ligand) $[22,98]$. In this regard, the Del-1 ${ }^{-1-}$ mice exhibited 3-fold higher RANKL expression in the gingiva than wild-type controls, 
although both groups had similar expression of the RANKL inhibitor, osteoprotegerin.

These findings indicate that Del-1 deficiency causes periodontal bone loss that is dependent on LFA-1-dependent neutrophil recruitment and IL-17R signaling. Moreover, conditions that restore tissue homeostasis in terms of periodontal bone maintenance (i.e., dual Del-1/LFA-1 or Del-1/IL-17R deficiencies) also reverse the numbers of oral bacteria to near normal levels.

Importantly, age-associated periodontal inflammation (including neutrophil accumulation and IL-17 production) was suppressed by local administration of Del-1. Del-1 is associated with the extracellular matrix and endothelial cell surface but not circulated in the blood [127]. It has recently shown that Del-1 is expressed in tissue specific-manner: very little expression in the kidney, none in the liver and a strong expression in the eye and brain [52], suggesting that Del-1 might be a key player in a certain tissues that may face unspecified immune response. Del-1 structure consists of five domains: repeat domains (E1, E2 and E3), three epidermal growth factors (EGF) at its $\mathrm{N}$-terminus and two discoidin domains at its C-terminus. E2 contains RGD sequence (Arg-Gly-Asp), which binds integrin $\alpha v \beta 3$ or $\alpha 5 \beta 3$ (Figure 24) [128]. The discoidin domains have been shown to be responsible for binding phosphatidyl serine-rich membranes. However, EGF like repeats have been shown to enable Del-1 to bind integrin [128]. Unlike many adhesion molecules, Del-1 inhibits the process of neutrophils binding to endothelial cells, thereby blocking entrance of neutrophils into inflamed tissues. Under normal flow physiologic conditions, addition of Del-1 to the system 
where neutrophils adhere onto immobilized ICAM-1 with activated LFA-1 suppresses the binding of neutrophils [52]. This finding implies that Del-1 may compete with ICAM-1 for the binding to LFA-1. All together, modulation of Del-1 expression could be a candidate therapeutic strategy for autoimmune and chronic inflammatory disease. However, the usage of Del-1 clinically would be so costly thereby it could not be afforded. Alternatively, some companies tried to make synthetic inhibitors or antibodies to inhibit ICAM-1/LFA-1 binding. The ICAM-1/LFA-1 interaction can be controlled at the site of LFA-1/ICAM interaction, the metal-ion-dependent adhesion site (MIDAS), or through binding to an allosteric site on LFA-1 [129] that causes it to adopt a conformation that cannot bind to ICAM-1 . For example, the LFA inhibitor (LFA878), which binds an allosteric site on LFA-1, has been shown to inhibit the interaction between ICAM1 and LFA-1 [130]. Therefore, we used the LFA-1 inhibitor (LFA878) or Del-1 to prevent alveolar bone resorption and found Del-1 was more protective than that of LFA878 (data not shown). Our findings could be explained by the fact that LFA878 is not a competitive inhibitor, unlike Del-1, its half-life is not long enough to block the ICAM-1/LFA-1 interaction or it obviously doesn't function as much as Del-1 does at the cellular level. It is highly possible that Del-1 could have activities that remain undiscovered. Since it contains EGF domain (Figure 24), it can induce a number of signaling that needs to be studied. Indeed, Del-1 has recently shown to induce apoptosis through its EGF domains [131]. It is, therefore, obvious that all synthetic inhibitors or antibodies, which are available commercially, will not function like Del-1 functions. 


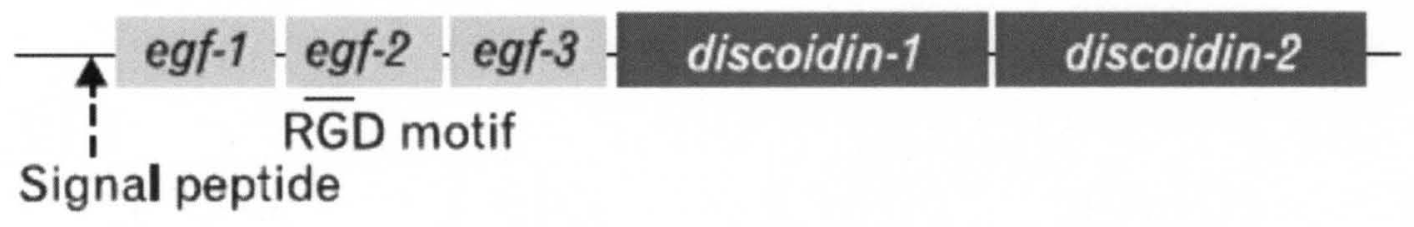

Immune Netw. 2009 Oct;9(5):153-7. Epub 2009 Oct 30.

Figure 24. Showing a domain structure of Del-1. Del-1 structure consists of five domains: repeat domains (E1, E2 and E3), three epidermal growth factors (EGF) at its $\mathrm{N}$-terminus and two discoidin domains at its $\mathrm{C}$-terminus. E2 contains RGD sequence (Arg-Gly-Asp), which binds integrin $\alpha v \beta 3$ or $\alpha 5 \beta 3$. 
Finally, our preliminary human results showed that Del-1 expression was dramatically reduced in diseased area as compared to healthy areas. We also found, in contrast to reduced De-1 expression, that IL-17 expression was markedly increased in diseased areas. Those results were completely consistent what we have found in old or Del-1 deficient mice. Del-1 could be associated with a spectrum of age-associated diseases whose onset and course may be influenced by pro-inflammatory cytokines. The finding that reduced Del-1 expression in old mice is capable of substantially augmenting bone loss. These data provide important evidence of one of key mechanisms through which reduced Del-1 expression may have potent health consequences for older adults, accelerating risk of a host of age-related diseases.

Overall, the main conclusions could be summarized as follows:

- Del-1 is a homeostatic regulator of chronic tissue inflammation involving LFA-1 integrin-dependent neutrophil recruitment and IL-17 receptor signaling.

- Del-1 expression is diminished in old age leading to periodontal inflammation and bone loss.

- Local administration of Del-1 reverses periodontal inflammation and may thus be a promising novel therapeutic for the treatment of periodontitis.

- Our preliminary human data showed that Del-1 expression was higher in healthy gingivae than diseased sites. In contrast, IL-17 expression was lower in healthy sites than disease sites. 
Together, Del-1 inhibits LFA-1-dependent neutrophil recruitment and IL17-mediated pathology and may be a promising novel therapeutic for trating diseases related to excessive or deficient recruitment of neutrophils. If excessive recruitment is desired (infectious disease), a strategy to block Del-1 should be taken. In contrast, if excessive neutrohil is the issue, a strategy to boost Del-1 should be taken. 


\section{REFERENCES:}

1. Pittman, J., Effect of aging on wound healing: current concepts. J Wound Ostomy Continence Nurs, 2007. 34(4): p. 412-5; quiz 416-7.

2. Huttner, E.A., et al., Effects of human aging on periodontal tissues. Spec Care Dentist, 2009. 29(4): p. 149-55.

3. Kornman, K.S., Interleukin 1 genetics, inflammatory mechanisms, and nutrigenetic opportunities to modulate diseases of aging. Am J Clin Nutr, 2006. 83(2): p. 475S-483S.

4. Gaffen, S.L. and G. Hajishengallis, A new inflammatory cytokine on the block: rethinking periodontal disease and the Th1/Th2 paradigm in the context of Th17 cells and IL-17. J Dent Res, 2008. 87(9): p. 817-28.

5. Fransson, C., T. Berglundh, and J. Lindhe, The effect of age on the development of gingivitis. Clinical, microbiological and histological findings. J Clin Periodontol, 1996. 23(4): p. 379-85.

6. Linton, P.J. and K. Dorshkind, Age-related changes in lymphocyte development and function. Nat Immunol, 2004. 5(2): p. 133-139.

7. Kovacs, E.J., et al., Aging and innate immunity in the mouse: impact of intrinsic and extrinsic factors. Trends Immunol, 2009. 30(7): p. 319-24.

8. Kinane, D.F. and T.C. Hart, Genes and gene polymorphisms associated with periodontal disease. Crit Rev Oral Biol Med, 2003. 14(6): p. 430-49.

9. Molvig, J., et al., Endotoxin-stimulated human monocyte secretion of interleukin 1, tumour necrosis factor alpha, and prostaglandin E2 shows stable interindividual differences. Scand J Immunol, 1988. 27(6): p. 705-16.

10. Shapira, L., et al., The secretion of PGE2, IL-I beta, IL-6, and TNF alpha by adherent mononuclear cells from early onset periodontitis patients. J Periodontol, 1994. 65(2): p. 139-46.

11. Garrison, S.W. and F.C. Nichols, LPS-elicited secretory responses in monocytes: altered release of PGE2 but not IL-1 beta in patients with adult periodontitis. $\mathrm{J}$ Periodontal Res, 1989. 24(2): p. 88-95.

12. Kasama, T., et al., Neutrophil-derived cytokines: potential therapeutic targets in inflammation. Curr Drug Targets Inflamm Allergy, 2005. 4(3): p. 273-9.

13. Hartl, D., et al., Infiltrated neutrophils acquire novel chemokine receptor expression and chemokine responsiveness in chronic inflammatory lung diseases. $\mathrm{J}$ Immunol, 2008. 181(11): p. 8053-67.

14. Kempf, T., et al., GDF-15 is an inhibitor of leukocyte integrin activation required for survival after myocardial infarction in mice. Nat Med, 2011. 17(5): p. 581-8.

15. Page, R.C. and H.E. Schroeder, Pathogenesis of inflammatory periodontal disease. A summary of current work. Lab Invest, 1976. 34(3): p. 235-49. 
16. Nussbaum, G. and L. Shapira, How has neutrophil research improved our understanding of periodontal pathogenesis? Journal of Clinical Periodontology, 2011. 38: p. 49-59.

17. Gemmell, E., R.I. Marshall, and G.J. Seymour, Cytokines and prostaglandins in immune homeostasis and tissue destruction in periodontal disease. Periodontology 2000, 1997. 14(1): p. 112-143.

18. Pasparakis, M., Regulation of tissue homeostasis by NF-[kappa]B signalling: implications for inflammatory diseases. Nat Rev Immunol, 2009. 9(11): p. 778-788.

19. Nussbaum, G. and L. Shapira, How has neutrophil research improved our understanding of periodontal pathogenesis? J Clin Periodontol, 2011. 38 Suppl 11: p. 49-59.

20. Appelberg, R., Neutrophils and intracellular pathogens: beyond phagocytosis and killing. Trends Microbiol, 2007. 15(2): p. 87-92.

21. Johnson, R.B., N. Wood, and F.G. Serio, Interleukin-11 and IL-17 and the pathogenesis of periodontal disease. J Periodontol, 2004. 75(1): p. 37-43.

22. Lubberts, E., IL-17/Th17 targeting: on the road to prevent chronic destructive arthritis? Cytokine, 2008. 41(2): p. 84-91.

23. Roussel, L., et al., IL-17 Promotes p38 MAPK-Dependent Endothelial Activation Enhancing Neutrophil Recruitment to Sites of Inflammation. The Journal of Immunology. 184(8): p. 4531-4537.

24. Iwakura, Y., et al., The roles of $I L-17 A$ in inflammatory immune responses and host defense against pathogens. Immunological Reviews, 2008. 226(1): p. 57-79.

25. Oda, N., et al., Interleukin- $17 F$ induces pulmonary neutrophilia and amplifies antigen-induced allergic response. Am J Respir Crit Care Med, 2005. 171(1): p. 12-8.

26. Kolls, J.K. and A. Linden, Interleukin-17 family members and inflammation. Immunity, 2004. 21(4): p. 467-76.

27. Stark, M.A., et al., Phagocytosis of apoptotic neutrophils regulates granulopoiesis via IL-23 and IL-17. Immunity, 2005. 22(3): p. 285-94.

28. Gaffen, S.L., Structure and signalling in the $I L-17$ receptor family. Nat Rev Immunol, 2009. 9(8): p. 556-67.

29. Pappu, R., V. Ramirez-Carrozzi, and A. Sambandam, The interleukin-17 cytokine family: critical players in host defence and inflammatory diseases. Immunology, 1111. 2011(4): p. 1365-2567.

30. Hu, Y., et al., The IL-17 pathway as a major therapeutic target in autoimmune diseases. Annals of the New York Academy of Sciences, $2011.1217(1)$ : p. 60-76.

31. Linden, A., M. Laan, and G.P. Anderson, Neutrophils, interleukin-17A and lung disease. Eur Respir J, 2005. 25(1): p. 159-72.

32. Miossec, P., Interleukin-17 in rheumatoid arthritis: If T cells were to contribute to inflammation and destruction through synergy. Arthritis \& Rheumatism, 2003. 48(3): p. 594-601.

33. Takaya, H., et al., Interleukin-17 stimulates chemokine (interleukin-8 and monocyte chemoattractant protein-1) secretion in human pancreatic periacinar myofibroblasts. Scand J Gastroenterol, 2002. 37(2): p. 239-45.

34. Oseko, F., et al., IL-17 is involved in bone resorption in mouse periapical lesions. Microbiol Immunol, 2009. 53(5): p. 287-94. 
35. Lubberts, E., et al., Treatment with a neutralizing anti-murine interleukin-17 antibody after the onset of collagen-induced arthritis reduces joint inflammation, cartilage destruction, and bone erosion. Arthritis \& Rheumatism, 2004. 50(2): p. 650659.

36. Akamatsu, Y., et al., Porphyromonas gingivalis induces myocarditis and/or myocardial infarction in mice and IL-17A is involved in pathogenesis of these diseases. Arch Oral Biol. 2011: p. 15.

37. Pihlstrom, B.L., B.S. Michalowicz, and N.W. Johnson, Periodontal diseases. Lancet, 2005. 366(9499): p. 1809-20.

38. Natarajan, M., et al., A global analysis of cross-talk in a mammalian cellular signalling network. Nat Cell Biol, 2006. 8(6): p. 571-80.

39. Leibovich, S.J., et al., Synergistic Up-Regulation of Vascular Endothelial Growth Factor Expression in Murine Macrophages by Adenosine A2A Receptor Agonists and Endotoxin. Am J Pathol, 2002. 160(6): p. 2231-2244.

40. Ley, K., et al., Getting to the site of inflammation: the leukocyte adhesion cascade updated. Nat Rev Immunol, 2007. 7(9): p. 678-89.

41. Borregaard, N., Neutrophils, from marrow to microbes. Immunity, 2010. 33(5): p. 657-70.

42. Luster, A.D., R. Alon, and U.H. von Andrian, Immune cell migration in inflammation: present and future therapeutic targets. Nat. Immunol., 2005. 6(12): p. $1182-90$.

43. Chavakis, E., E.Y. Choi, and T. Chavakis, Novel aspects in the regulation of the leukocyte adhesion cascade. Thromb Haemost, 2009. 102(2): p. 191-7.

44. Langer, H.F. and T. Chavakis, Leukocyte - endothelial interactions in inflammation. Journal of Cellular and Molecular Medicine, 2009. 13(7): p. 1211-1220.

45. Kelly, D., et al., Commensal anaerobic gut bacteria attenuate inflammation by regulating nuclear-cytoplasmic shuttling of PPAR-gamma and RelA. Nat Immunol, 2004. 5(1): p. 104-12.

46. McEver, R.P. and C. Zhu, A catch to integrin activation. Nat Immunol, 2007. 8(10): p. 1035-7.

47. Salas, A., et al., Rolling adhesion through an extended conformation of integrin alphaLbeta 2 and relation to alpha I and beta I-like domain interaction. Immunity, 2004. 20(4): p. 393-406.

48. Smith, A., et al., Selective suppression of IL-12 production by human herpesvirus 6. Blood, 2003. 102(8): p. 2877-2884.

49. Basit, A., et al., ICAM-1 and LFA-1 play critical roles in LPS-induced neutrophil recruitment into the alveolar space. Am J Physiol Lung Cell Mol Physiol, 2006. 291(2): p. L200-7.

50. Sarantos, M.R., et al., Transmigration of neutrophils across inflamed endothelium is signaled through LFA-1 and Src family kinase. J Immunol, 2008. 181(12): p. 8660-9.

51. Daley, J.M., et al., Use of Ly6G-specific monoclonal antibody to deplete neutrophils in mice. J Leukoc Biol, 2008. 83(1): p. 64-70.

52. Choi, E.Y., et al., Del-1, an endogenous leukocyte-endothelial adhesion inhibitor, limits inflammatory cell recruitment. Science, 2008. 322(5904): p. 1101-4. 
53. Eniola-Adefeso, O., R. Huang, and C. Smith, Kinetics of LFA-1 Mediated Adhesion of Human Neutrophils to ICAM-1-Role of E-Selectin Signaling PostActivation. Annals of Biomedical Engineering, 2009. 37(4): p. 737-748.

54. Onan, D., et al., The chemokine Cxcll is a novel target gene of parathyroid hormone (PTH)/PTH-related protein in committed osteoblasts. Endocrinology, 2009. 150(5): p. 2244-53.

55. Tsai, W.C., et al., Lung-specific transgenic expression of $K C$ enhances resistance to Klebsiella pneumoniae in mice. J Immunol, 1998. 161(5): p. 2435-40.

56. Salvi, G.E. and N.P. Lang, Host response modulation in the management of periodontal diseases. J Clin Periodontol, 2005. 32 Suppl 6: p. 108-29.

57. Webb, A., et al., Evidence for PI-3K-dependent migration of Th17-polarized cells in response to CCR2 and CCR6 agonists. J Leukoc Biol, 2008. 84(4): p. 1202-12.

58. Pelletier, M., et al., Evidence for a cross-talk between human neutrophils and Th1 7 cells. Blood, 2009.

59. Skerrett, S.J., et al., Redundant Toll-like receptor signaling in the pulmonary host response to Pseudomonas aeruginosa. Am. J. Physiol. Lung Cell. Mol. Physiol., 2007. 292(1): p. L312-22.

60. Bennouna, S., et al., Cross-talk in the innate immune system: neutrophils instruct recruitment and activation of dendritic cells during microbial infection. J Immunol, 2003. 171(11): p. $6052-8$.

61. Hirota, K., et al., Preferential recruitment of CCR6-expressing Th17 cells to inflamed joints via CCL20 in rheumatoid arthritis and its animal model. J Exp Med, 2007. 204(12): p. 2803-12.

62. Hidai, C., et al., Discoidin domain of Dell protein contributes to its deposition in the extracellular matrix. Cell Tissue Res, 2007. 330(1): p. 83-95.

63. Acosta-Rodriguez, E.V., et al., Surface phenotype and antigenic specificity of human interleukin 17-producing $T$ helper memory cells. Nat Immunol, 2007. 8(6): p. 639-646.

64. Alayan, J., S. Ivanovski, and C.S. Farah, Alveolar bone loss in Thelper 1/T helper 2 cytokine-deficient mice. J. Periodont. Res., 2007. 42(2): p. 97-103.

65. Stockinger, B., M. Veldhoen, and B. Martin, Th17 T cells: linking innate and adaptive immunity. Semin Immunol, 2007. 19(6): p. 353-61.

66. Bettelli, E., T. Korn, and V.K. Kuchroo, Th17: the third member of the effector $T$ cell trilogy. Curr Opin Immunol, 2007. 19(6): p. 652-7.

67. McGeachy, M.J., et al., TGF-[beta] and IL-6 drive the production of IL-17 and IL-10 by $T$ cells and restrain TH-17 cell-mediated pathology. Nat Immunol, 2007. 8(12): p. $1390-1397$.

68. Kimura, Y., et al., Activator-specific requirement of properdin in the initiation and amplification of the alternative pathway complement. Blood, 2008. 111(2): p. 732740.

69. Conti, H.R., et al., Th17 cells and IL-17 receptor signaling are essential for mucosal host defense against oral candidiasis, 2009. p. 299-311.

70. Miossec, P., T. Korn, and V.K. Kuchroo, Interleukin-17 and type 17 helper $T$ cells. N Engl J Med, 2009. 361(9): p. 888-98.

71. Graves, D., Cytokines that promote periodontal tissue destruction. J Periodontol, 2008. 79(8 Suppl): p. 1585-91. 
72. Hanayama, R., et al., Expression of developmental endothelial locus- 1 in a subset of macrophages for engulfment of apoptotic cells. J Immunol, 2004. 172(6): p. 3876-82.

73. Deban, L., et al., Regulation of leukocyte recruitment by the long pentraxin PTX3. Nat Immunol, 2010. 11(4): p. 328-34.

74. Liang, S., et al., Periodontal inflammation and bone loss in aged mice. $\mathrm{J}$ Periodontal Res, 2010. 45(4): p. 574-8.

75. Burt, B.A., Periodontitis and aging: reviewing recent evidence. J Am Dent Assoc, 1994. 125(3): p. 273-9.

76. Desvarieux, M., et al., Periodontal microbiota and carotid intima-media thickness: the Oral Infections and Vascular Disease Epidemiology Study (INVEST). Circulation, 2005. 111(5): p. 576-82.

77. Gibson, F.C., 3rd, et al., Innate immune recognition of invasive bacteria accelerates atherosclerosis in apolipoprotein E-deficient mice. Circulation, 2004. 109(22): p. 2801-2806.

78. Ye, P., et al., Requirement of interleukin 17 receptor signaling for lung CXC chemokine and granulocyte colony-stimulating factor expression, neutrophil recruitment, and host defense. J Exp Med, 2001. 194(4): p. 519-27.

79. Ding, Z.M., et al., Relative contribution of LFA-1 and Mac-1 to neutrophil adhesion and migration. J Immunol, 1999. 163(9): p. 5029-38.

80. Wang, M., et al., Fimbrial proteins of Porphyromonas gingivalis mediate in vivo virulence and exploit TLR2 and complement receptor 3 to persist in macrophages. J. Immunol., 2007. 179(4): p. 2349-2358.

81. Baker, P.J., M. Dixon, and D.C. Roopenian, Genetic control of susceptibility to Porphyromonas gingivalis-induced alveolar bone loss in mice. Infect. Immun., 2000. 68(10): p. 5864-5868.

82. Gomez, C.R., et al., Innate immunity and aging. Exp Gerontol, 2008. 43(8): p. 718-28.

83. Pawelec, G. and A. Larbi, Immunity and ageing in man: Annual Review 2006/2007. Exp Gerontol, 2008. 43(1): p. 34-8.

84. Hajishengallis, G., Too old to fight? Aging and its toll on innate immunity. Mol Oral Microbiol, 2010. 25(1): p. 25-37.

85. Simpson, J.L., S. Phipps, and P.G. Gibson, Inflammatory mechanisms and treatment of obstructive airway diseases with neutrophilic bronchitis. Pharmacol Ther, 2009. 124(1): p. 86-95.

86. Cascão, R., et al., Neutrophils in rheumatoid arthritis: More than simple final effectors. Autoimmunity Reviews, 2010. 9(8): p. 531-535.

87. Van Dyke, T.E. and C.N. Serhan, Resolution of inflammation: a new paradigm for the pathogenesis of periodontal diseases. J. Dent. Res., 2003. 82(2): p. 82-90.

88. Darveau, R.P., Periodontitis: a polymicrobial disruption of host homeostasis. Nat Rev Microbiol, 2010. 8(7): p. 481-90.

89. Cua, D.J. and C.M. Tato, Innate IL-17-producing cells: the sentinels of the immune system. Nat Rev Immunol, 2010. 10(7): p. 479-89.

90. Fan, Y., et al., Del-1 gene transfer induces cerebral angiogenesis in mice. Brain Research, 2008. 1219: p. 1-7.

91. Graves, D.T., et al., The use of rodent models to investigate host-bacteria interactions related to periodontal diseases. J Clin Periodontol, 2008. 35(2): p. 89-105. 
92. Cascao, R., et al., Neutrophils in rheumatoid arthritis: More than simple final effectors. Autoimmun Rev, 2010.9(8): p. 531-5.

93. Lester, S.R., et al., Gingival concentrations of interleukin-23 and -17 at healthy sites and at sites of clinical attachment loss. J Periodontol, 2007. 78(8): p. 1545-50.

94. Ohyama, H., et al., The involvement of $I L-23$ and the ThI7 pathway in periodontitis. J Dent Res, 2009. 88(7): p. 633-8.

95. Cardoso, C.R., et al., Evidence of the presence of Thelper type 17 cells in chronic lesions of human periodontal disease. Oral Microbiol Immunol, 2009. 24(1): p. 1-6.

96. Trombone, A.P., et al., Experimental periodontitis in mice selected for maximal or minimal inflammatory reactions: increased inflammatory immune responsiveness drives increased alveolar bone loss without enhancing the control of periodontal infection. J Periodontal Res, 2009. 44(4): p. 443-51.

97. Yu, J.J., et al., An essential role for $I L-17$ in preventing pathogen-initiated bone destruction: recruitment of neutrophils to inflamed bone requires $I L-17$ receptordependent signals. Blood, 2007. 109(9): p. 3794-802.

98. Gaffen, S.L., The role of interleukin-17 in the pathogenesis of rheumatoid arthritis. Curr Rheumatol Rep, 2009. 11(5): p. 365-70.

99. Chakravarti, A., et al., Surface RANKL of Toll-like receptor 4-stimulated human neutrophils activates osteoclastic bone resorption. Blood, 2009. 114(8): p. 1633-1644.

100. Serhan, C.N., N. Chiang, and T.E. Van Dyke, Resolving inflammation: dual antiinflammatory and pro-resolution lipid mediators. Nat Rev Immunol, 2008. 8(5): p. 349361.

101. Happel, K.I., et al., Cutting edge: roles of Toll-like receptor 4 and IL-23 in IL-17 expression in response to Klebsiella pneumoniae infection. J Immunol, 2003. 170(9): p. 4432-6.

102. Martin, B., et al., Interleukin-17-producing gammadelta T cells selectively expand in response to pathogen products and environmental signals. Immunity, 2009. 31(2): p. 321-30.

103. Chakravarti, A., et al., Surface RANKL of Toll-like receptor 4-stimulated human neutrophils activates osteoclastic bone resorption. Blood, 2009. 114(8): p. 1633-44.

104. Poubelle, P.E., et al., Differential expression of RANK, RANK-L, and osteoprotegerin by synovial fluid neutrophils from patients with rheumatoid arthritis and by healthy human blood neutrophils. Arthritis Res Ther, 2007. 9(2): p. R25.

105. Rittirsch, D., M.A. Flierl, and P.A. Ward, Harmful molecular mechanisms in sepsis. Nat Rev Immunol, 2008. 8(10): p. 776-787.

106. Krauss, J.L., et al., Complementary Tolls in the periodontium: how periodontal bacteria modify complement and Toll-like receptor responses to prevail in the host. Periodontol 2000, 2010. 52: p. 141-162.

107. Brown, L.J., B.A. Johns, and T.P. Wall, The economics of periodontal diseases. Periodontol 2000, 2002. 29: p. 223-34.

108. Tonetti, M.S., et al., Treatment of periodontitis and endothelial function. N Engl J Med, 2007. 356(9): p. 911-20.

109. Genco, R.J. and T.E. Van Dyke, Prevention: Reducing the risk of CVD in patients with periodontitis. Nat Rev Cardiol, 2010. 7(9): p. 479-80.

110. van der Velden, U., The onset age of periodontal destruction. J Clin Periodontol, 1991. 18(6): p. 380-3. 
111. Franceschi, C., et al., Inflamm-aging. An evolutionary perspective on immunosenescence. Ann N Y Acad Sci, 2000. 908: p. 244-54.

112. Armitage, G.C., Classifying periodontal diseases--a long-standing dilemma. Periodontol 2000, 2002. 30: p. 9-23.

113. Gardner, E.M. and D.M. Murasko, Age-related changes in Type 1 and Type 2 cytokine production in humans. Biogerontology, 2002. 3(5): p. 271-90.

114. Frasca, D., et al., Regulation of cytokine production in aging: use of recombinant cytokines to upregulate mitogen-stimulated spleen cells. Mechanisms of Ageing and Development, 1997.93(1-3): p. 157-169.

115. Song, Y., et al,, Aging Enhances the Basal Production of IL-6 and CCL2 in Vascular Smooth Muscle Cells. Arteriosclerosis, Thrombosis, and Vascular Biology, 2011.

116. Anne, O.G., INTERLEUKINS AND THE IMMUNE SYSTEM 2. The Lancet, 1989. 333(8645): p. 1003-1005.

117. Donnelly, R., et al., Differential regulation of $I L-1$ production in human monocytes by IFN-gamma and IL-4. The Journal of Immunology, 1990. 145(2): p. 569575.

118. Del Prete, G., et al., Human IL-10 is produced by both type I helper (Th1) and type 2 helper (Th2) $T$ cell clones and inhibits their antigen-specific proliferation and cytokine production. The Journal of Immunology, 1993. 150(2): p. 353-360.

119. Punnonen, J., et al., Interleukin 13 induces interleukin 4-independent IgG4 and IgE synthesis and CD23 expression by human B cells. Proc Natl Acad Sci U S A, 1993. 90(8): p. 3730-4.

120. Santiago, A.F., et al., Aging correlates with reduction in regulatory-type cytokines and T cells in the gut mucosa. Immunobiology, 2011. 216(10): p. 1085-1093.

121. Fulop, T., et al., Signal transduction and functional changes in neutrophils with aging. Aging Cell, 2004. 3(4): p. 217-226.

122. Fortin, C.F., et al., Impairment of SHP-1 down-regulation in the lipid rafts of human neutrophils under GM-CSF stimulation contributes to their age-related, altered functions. J Leukoc Biol, 2006. 79(5): p. 1061-72.

123. Fortin, C.F., O. Lesur, and T. Fulop, Jr., Effects of aging on triggering receptor expressed on myeloid cells (TREM)-1-induced PMN functions. FEBS Lett, 2007. 581(6): p. 1173-8.

124. Fulop, T., et al., The Role of Mcl-1 and Bax Expression Alteration in the Decreased Rescue of Human Neutrophils from Apoptosis by GM-CSF with Aging. Annals of the New York Academy of Sciences, 2002. 973(1): p. 305-308.

125. Henson, P.M., D.L. Bratton, and V.A. Fadok, Apoptotic cell removal. Current Biology, 2001. 11(19): p. R795-R805.

126. Hajishengallis, G., Too old to fight? Aging and its toll on innate immunity. Mol. Oral Microbiol., 2010. 25: p. 25-37.

127. Choi, E.Y., Inhibition of leukocyte adhesion by developmental endothelial locus-1 (del-1). Immune Netw, 2009. 9(5): p. 153-7.

128. Hidai, C., et al., Cloning and characterization of developmental endothelial locus1: an embryonic endothelial cell protein that binds the alphavbeta3 integrin receptor. Genes Dev, 1998. 12(1): p. 21-33. 
129. Luo, B.H., C.V. Carman, and T.A. Springer, Structural basis of integrin regulation and signaling. Annu. Rev. Immunol., 2007.

130. Weitz-Schmidt, G., et al., Improved Lymphocyte Function-associated Antigen-1 (LFA-1) Inhibition by Statin Derivatives. Journal of Biological Chemistry, 2004. 279(45): p. 46764-46771.

131. Kitano, H., S. Kokubun, and C. Hidai, The extracellular matrix protein Dell induces apoptosis via its epidermal growth factor motif. Biochemical and Biophysical Research Communications, 2010.393(4): p. 757-761. 


\title{
CURRICULUM VITAE
}

\author{
Mehmet "Akif" ESKAN, D.D.S. \\ Clinical Assistant Professor \\ School of Dentistry, Oral Health and Rehabilitation, Division of Periodontics, \\ 501 South Preston Street, Room 312 \\ University of Louisville, Louisville, KY 40202 \\ Cell : (502) 418-2783 \\ Work : (502) 852-6928 \\ Fax : (502) 852-1317 \\ E-mail : maeska02@gwise.louisville.edu
}

\section{Education:}

Sep 1992 - July 1997 : DDS, Faculty of Dentistry, Hacettepe University Ankara, TURKEY

Sep 1988 - Jun 1992 : Bachelor's Degree Bayburt, TURKEY

July 2008 - July 2011 : Certificate in Periodontics, School of Dentistry, University of Louisville

Oct 2009-Nov $2011 \quad$ : PhD, Microbiology and Immunology, School of Medicine, University of Louisville. 


\section{Professional Work Experience}

Aug 2011-present

Dec 2007- July 2008
Clinical Assistant Professor,

\section{Research Associate}

Oral and Systemic Disease Research Center Dept of Periodontics, Endodontics and Dental Hygiene, School of Dentistry, University of Louisville.

Post Doctoral Fellow

Oral and Systemic Disease Research Center Dept of Periodontics, Endodontics and Dental Hygiene School of Dentistry, University of Louisville.

Oct 2002 - Mar 2005

Research Fellow, Institute for Cellular Therapeutics School of Medicine, University of Louisville.

Dec 2001 - Oct 2002 Dental Practice Istanbul-TURKEY

Sep 2001 - Dec 2001 Observer, College of Dentistry, University of Kentucky.

Jun 1999 - Sep $2001 \quad$ Dental Practice (private practice) Istanbul, TURKEY

Jun 1998 - May 1999 General Dentistry, Private hospital, Istanbul, TURKEY 
Awards:

2011: Southern Academy of Periodontology, First Place in Clinical poster competition.

2008: The Dean Scholarship, School of Dentistry, University of Louisville

2008: American Academy of Periodontology, Tarrson Regeneration Scholarship.

1998: Former President Honor Student Award, Hacettepe University.

1997: Honor First Grade Student Award, Hacettepe University.

1997: President's Superior Student Success Grade Award, Hacettepe University.

1997: Superior Grade Award from Turkish Dental Association.

1997: Dean's Superior Student Success Grade Award, Dentistry, Hacettepe University.

U.S. National Dental Board Examinations:

Step-1 Reference Number : 138413. Step-1: passed in Sep 2003

Step-2 Reference Number : 138413. Step-2: passed in Jan 2004

Memberships:

1- American Academy of Peridontology

2- American Academy of Osseointegration 


\section{Publications:}

1- Kinane, DF., H. Shiba, PG. Stathopoulou, H. Zhao, DF. Lappin, A. Singh, Eskan MA, S. Beckers, S. Waigel, B. Alpert, and TB. Knudsen. Gingival epithelial cells heterozygous for Toll-like receptor 4 polymorphisms Asp299Gly and Thr399lle are hypo-responsive to Porphyromonas gingivalis. 2006 Genes Immun.

2- Eskan MA, Hajishengallis, G. \& Kinane, DF. Differential Activation of Human Gingival Epithelial Cells and Monocytes by Porphyromonas gingivalis Fimbriae. 2007 Infect Immun

3- Eskan MA, Rose BG, Benakanakere M, Lee MJ, Kinane DF. Sphingosine 1-Phosphate 1 (S1P1) and TLR4 receptors mediate IFN- $\beta$ expression in human gingival epithelial cells 2008. J. Immunology

4- Eskan MA, Benakanakere $M$, Rose $B G$, Zhang $P$, Stathopoulou $P$, Fujioka $D$, Kinane DF. IL-1 $\beta$ modulates proinflammatory cytokine production in human epithelial cells. 2008 Infect Immun

5- Eskan MA, Rose BG, Benakanakere M, Zeng Q, Fujioka D, Martin M, Lee MJ, Kinane DF. S1P and TLR4 Receptors enhance Inflammatory Cytokine Production in Human Gingival Epithelial Cells. 2008 Eur J Immunol

6- Benakanakere MR, Li Q, Eskan MA, Singh AV, Zhao J, Galicia JC, Stathopoulou P, Knudsen TB, Kinane DF. Modulation of TLR2 protein expression by miR-105 in human oral keratinocytes. $2009 \mathrm{~J}$ Biol Chem.

7- Eskan MA, Greenwell $H$. Theoretical and Clinical Considerations for Autologous Blood Preparations: Platelet-Rich Plasma, Fibrin Sealants, and Plasma-Rich Growth Factors (review). 2011 Clinical Advances in Periodontics

8- Krauss JK, Liang S, Mclntosh ML, Eskan MA, and Hajishengallis, G., Mouse models of periodontal host-pathogen interactions and inflammation. Methods in Molecular Biology: Periodontal DiseaseMethods and Protocols. 2011.

9- Hajishengallis, G., S. Liang, M.A. Payne, A. Hashim, R. Jotwani, Eskan, MA., M.L. Mclntosh, A. Alsam, K.L. Kirkwood, J.D. Lambris, R.P. Darveau, and M.A. Curtis. Low-abundance biofilm species orchestrates 
inflammatory periodontal disease through the commensal microbiota complement. Cell Host \& Microbe, in press (2011). NIHMS332071

10-Eskan MA, Jotwani R, Abe T, Liang S, Ciero PA, Li F, Chung KJ, Chavakis $T$, Hajishengallis G., Developmental endothelial locus-1 (Del-1) is required for prevention of interleukin-17-mediated pathology (Immunity, under revision).

\section{Presentations:}

Synergy between TLR4 and S1P 1 enhances Oral Epithelial Cell Integrity. MA ESKAN, BG ROSE, Q ZENG, MJ LEE and DF KINANE. (Innate Immun, San Antonio 2006)

TLR4 gene variants results in cytokine production differences following Porphyromonas qingivalis challenge. M BENAKANAKERE, MA ESKAN, D FUJIOKA, P ZHANG, PG. STATHOPOULOU, B ROSE, and DF. KINANE (Innate Immun, San Antonio 2006)

Differential Activation of Human Gingival Epithelial Cells and Monocytes by Porphyromonas ginqivalis. MA ESKAN, G HAJISHENGALLIS, and DF KINANE (Gordon, Periodontal dieseaes, Italy 2006)

Common TLR4 polymorphisms influence NALP3 and caspase-1 in epithelial cells. MA ESKAN, M BENAKANAKERE, and DF KINANE (AADR/IADR, New Orleans 2007)

Proinflammatory Responses Elicited by Four Periodontal Bacteria. P.G. STATHOPOULOU, D. FUJIOKA, MA ESKAN, P ZHANG, M BENAKANAKERE, $B$ ROSE, and DF KINANE (AADR, IADR, New Orleans 2007)

MicroRNAs miR-128a and miR-146a Regulate Cytokines in Gingival Epithelial Cells. M BENAKANAKERE, MA ESKAN, D FUJIOKA, P ZHANG, PG. STATHOPOULOU, B ROSE, and DF. KINANE. (AADR, IADR, New Orleans 2007)

Age-related TLR4 and Sphingosine 1-Phosphate Functionality in Gingival Epithelial Cells. MA ESKAN, B ROSE, Q ZENG, MJ LEE, and DF KINANE (AADR, IADR, New Orleans 2007) 
CD14/TLR2 complex induction by $P$. gingivalis fimbriae in lipid rafts. G.HAJISHENGALLIS, S LIANG 1, MA. ESKAN, M TRIANTAFILOU DF KINANE, and K TRIANTAFILOU (AADR, IADR, New Orleans 2007)

Detecting Periodontal and Oral Bacterial from Blood Samples by gPCR. P. ZHANG, M BENAKANAKERE, B ROSE, MA ESKAN, D FUJIOKA, PG. STATHOPOULOU, and DF. KINANE (AADR, IADR, New Orleans 2007)

Epithelial TLR4 Levels Correlate With Cytokine and Antimicrobial Peptide Production. DF KINANE, SU GORR, PG. STATHOPOULOU, D FUJIOKA, MA ESKAN, P ZHANG, M BENAKANAKERE, and B ROSE (AADR, IADR, New Orleans 2007)

Sphingosine 1-Phosphate and LPS in the induction of Interferon beta in epithelial cells. MA ESKAN, BG ROSE, M BENAKANAKERE, MJ LEE, DF KINANE (Innate Immunity, Ankara 2007)

Genotypes and systemic inflammatory molecules in experimental gingivitis. ZHANG $P$, BENAKANAKERE MR, ROSE BG, ESKAN MA, STATHOPOULOU P and KINANE DF. (IADR, Toronto 2008)

Sphingosine Kinase 1 requlated $H B D-2$ induction in oral keratinocytes. $M$ BENAKANAKERE, Q LI, J ZHAO, MA ESKAN, PG. STATHOPOULOU, J GALICIA, and DF KINANE (IADR, Toronto 2008)

mic-105 modulates TLR2 expression in oral keratinocytes. $M$ BENAKANAKERE, Q LI, J ZHAO, MA ESKAN, PG. STATHOPOULOU, J GALICIA, and DF KINANE. (IADR, Toronto 2008). 